Cite this: J. Mater. Chem. C, 2013, 1, 1638

Received 23rd October 2012 Accepted 29th December 2012

DOI: $10.1039 / \mathrm{c} 2 \mathrm{tc00474g}$

www.rsc.org/MaterialsC

\title{
Bis(carbazolyl) derivatives of pyrene and tetrahydropyrene: synthesis, structures, optical properties, electrochemistry, and electroluminescencet
}

\author{
Bilal R. Kaafarani, ${ }^{\text {*a }}$ Ala'a O. El-Ballouli, ${ }^{\text {a }}$ Roman Trattnig, ${ }^{\text {b }}$ Alexandr Fonari, ${ }^{c}$

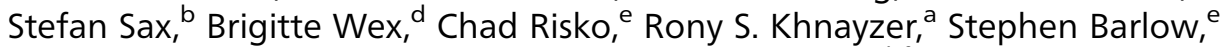 \\ Digambara Patra, ${ }^{a}$ Tatiana V. Timofeeva, ${ }^{c}$ Emil J. W. List, ${ }^{\text {bf }}{ }^{\prime}$ Jean-Luc Brédas ${ }^{\mathrm{e}}$ \\ and Seth R. Marder
}

Tetrahydropyrene and pyrene have been functionalized in their 2,7-positions with carbazole and 3,6-ditert-butylcarbazole groups, and the properties of these new compounds are compared to analogous carbazole and 3,6-di-tert-butylcarbazole derivatives of benzene and biphenyl using X-ray crystallography, UV-vis absorption and fluorescence spectroscopy, electrochemistry, and quantumchemical calculations. The absorption spectra are similar to those of their biphenyl-bridged analogues, although TD-DFT calculations indicate a different description of the excited states in the pyrene case, with the lowest observed absorption no longer corresponding to the $\mathrm{S}_{0} \rightarrow \mathrm{S}_{1}$ transition. The 3,6-di-tertbutylcarbazole compounds show reversible electrochemical oxidations; the benzene, biphenyl, tetrahydropyrene, or pyrene bridging groups have little impact on the first oxidation potential. Bilayer organic light-emitting diodes incorporating the tetrahydropyrene and pyrene derivatives as emitters show deep-blue electroluminescence.

\section{Introduction}

Organic electroluminescent devices are of interest for use in flat panel displays and for lighting. ${ }^{1-3}$ Full-color displays require the use of red, green, and blue emitters; relative to red and green emitters, blue emitters are not as well optimized in terms of their efficiency, color purity, and stability..$^{4-7}$ Efficient charge injection from electrodes into the adjacent organic layers, balanced charge transport, confinement of hole-electron recombination and the resultant excitons in the desired

\footnotetext{
${ }^{a}$ Department of Chemistry, American University of Beirut, Beirut 1107-2020, Lebanon. E-mail: bilal.kaafarani@aub.edu.lb; Tel: +961-3151451

${ }^{b}$ NanoTecCenter Weiz Forschungsgesellschaft mbH, Franz-Pichler-Straße 32, A-8160 Weiz, Austria

${ }^{c}$ Department of Biology \& Chemistry, New Mexico Highlands University, Las Vegas, NM 87701, USA

${ }^{d}$ Department of Natural Sciences, Lebanese American University, Byblos, Lebanon ${ }^{e}$ School of Chemistry and Biochemistry and Center for Organic Photonics and Electronics, Georgia Institute of Technology, Atlanta, Georgia 30332, USA

${ }^{f}$ Institut für Festkörperphysik, Technische Universität Graz, Petersgasse 16, A-8010 Graz, Austria

† Electronic supplementary information (ESI) available: Packing diagrams, select bond angles and dihedral angles of the ground state and radical-cation states, absorption and emission data in different solvents, frontier molecular orbitals, CV plots, DSC plots, ${ }^{1} \mathrm{H}$ NMR spectra, and cif files. CCDC 899423-899426. For ESI and crystallographic data in CIF or other electronic format See DOI: $10.1039 / \mathrm{c} 2 \mathrm{tc} 00474 \mathrm{~g}$
}

emissive layer, and high quantum efficiencies of luminescence are all important factors in achieving efficient devices, which should ideally exhibit low drive voltages and high current and power efficiencies. ${ }^{8}$ Efficient blue-emitting devices are challenging to fabricate because the large optical and transport gap required for the emitter means that efficient hole and/or electron injection can be hard to achieve at moderate drive voltages, while care also has to be taken to avoid the possibility of exciton energy transfer from the emissive layer to neighboring materials. Blue OLEDs can be obtained by using either fluorescent or phosphorescent materials. Although the latter approach can potentially result in much higher quantum efficiency, successful implementation typically involves blending of a heavy-metal phosphorescent "guest" into an organic "host", both the singlet and triplet excited-state energy of which must be larger than that of the "guest", while triplet energy transfer to neighboring layers must be prevented, thus leading to even more challenging issues regarding injection and exciton confinement.

Polyaromatic molecules, such as diphenylanthracene, ${ }^{9}$ have been studied as potential fluorescent blue emitters. Pyrene has a remarkably long fluorescence lifetime, ${ }^{\mathbf{1 0}}$ yet also exhibits high photoluminescence (PL) efficiency. In addition, it has a strong tendency to form excimers, ${ }^{\mathbf{1 1}, 12}$ while pyrene excitation spectra are sensitive to microenvironment changes. ${ }^{13}$ Although pyrene has high charge-carrier mobility and a lower ionization 
potential than many other efficient blue emitters, for example polyfluorenes, facilitating hole injection, pyrene itself is generally unsuitable for use in OLEDs due to its tendency to crystallize. ${ }^{5}$ Accordingly, a number of functionalized pyrenes have been developed as blue emitters. ${ }^{14}$ For example, solutionprocessable blue-emissive layers in OLEDs have been obtained by incorporating the pyrene core in dendrimers or polymers. ${ }^{15-17}$

Carbazole-based materials have been widely used as donors in a variety of organic electronic devices and, in general, exhibit hole-transport properties, although hybrids with various acceptor moieties such as oxadiazoles, ${ }^{18-20}$ and even $4,4^{\prime}$ di(carbazol-9-yl)biphenyl ${ }^{21}$ (CBP, compound 2a in Fig. 1), are ambipolar to varying extents. In OLEDs, carbazole-based materials have been used as hole-transport materials, ${ }^{22-24}$ as emitters, ${ }^{19,22,25}$ and as hosts for other fluorescent ${ }^{26}$ or phosphorescent emitters., ${ }^{\mathbf{9} 20,27-29}$ Although carbazoles typically exhibit irreversible electrochemistry due to dimerization and polymerization of the corresponding radical cations at their 3,6-positions, ${ }^{30-32}$ blocking of those positions can suppress these reactions; moreover, 3,6-di(tert-butyl) substitution of the carbazole moieties of CBP (to give $2 \mathbf{b}$, Fig. 1) has also been reported to result in a significantly higher glass-transition temperature. ${ }^{9}$

Given the fluorescent properties of pyrene and the transport properties of carbazoles, combining these two motifs in a single molecule may offer an interesting combination of physical properties and, perhaps, a route to new electroluminescent materials. Indeed, several such examples with a variety of architectures have been reported; however, these materials have generally presented quite extensive conjugation resulting in green emission. ${ }^{33-37}$ Here, we report the synthesis, characterization, and electroluminescent properties of molecules in which two carbazole or 3,6-di-tert-butylcarbazole moieties are attached through the nitrogen atom to the 2,7 positions of pyrene (4a and $\mathbf{4 b}$, Fig. 1), which, in contrast to previously reported carbazole-pyrene materials, show blue fluorescence. We compare the structures, optical and electrochemical properties, orbital structure, and reorganization energies of $\mathbf{4 a , b}$ to those of analogous compounds in which the pyrene is replaced with tetrahydropyrene $(\mathbf{3 a}, \mathbf{b})$, biphenyl $(\mathbf{2 a}, \mathbf{b})$, or benzene $(\mathbf{1 a}, \mathbf{b})$.
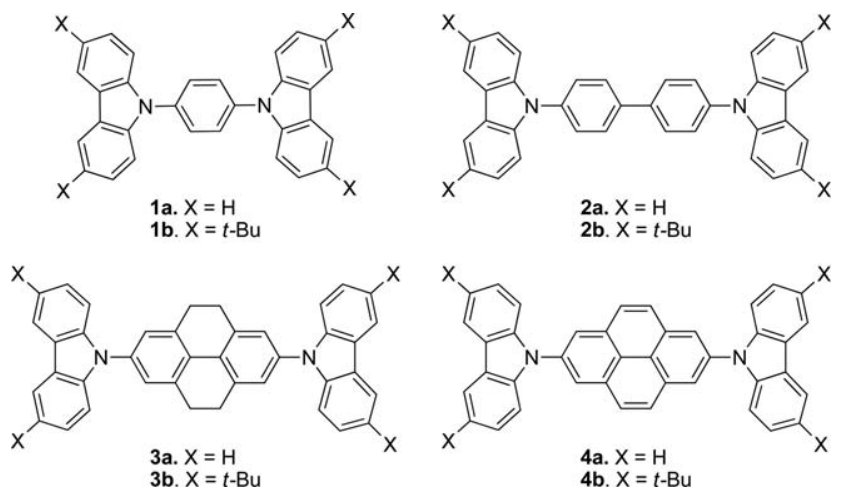

Fig. 1 Compounds studied in this work.

\section{Experimental}

\section{General}

The following compounds were synthesized according to literature procedures: 4,5,9,10-tetrahydropyrene, $6,^{38} \quad 2,7-$ dibromo-4,5,9,10-tetrahydropyrene, $7{ }^{39}$ 2,7-dibromopyrene, $8,{ }^{40}$ and 3,6-di-tert-butyl-9H-carbazole, $\mathbf{9 b} .^{41}$

\section{1,4-Bis(carbazol-9-yl)benzene (1a)}

Following a general literature procedure, ${ }^{42}$ a mixture of carbazole (1.00 g, $5.99 \mathrm{mmol})$, 1,4-dibromobenzene $(0.70 \mathrm{~g}, 2.9$ $\mathrm{mmol}$ ), copper powder (0.38 g, $5.9 \mathrm{mmol}), \mathrm{K}_{2} \mathrm{CO}_{3}(2.48 \mathrm{~g}, 17.9$ $\mathrm{mmol})$ and 18-crown-6 $(0.79 \mathrm{~g}, 2.9 \mathrm{mmol})$ were suspended in 1,2-dichlorobenzene $(30 \mathrm{~mL})$ and purged with argon for $30 \mathrm{~min}$. The reaction mixture was heated to reflux for $7 \mathrm{~d}$ under an argon atmosphere. The crude mixture was filtered and the residue was washed with $\mathrm{CHCl}_{3}(3 \times 10 \mathrm{~mL})$. The solid was precipitated by adding cold ethanol ( $c a .100 \mathrm{~mL}$ ) to the brown filtrate. The brown solid was then recrystallized from toluene-ethanol to obtain 1a as light brown solid ( $0.37 \mathrm{~g}, 34 \%$ ), mp (determined by DSC) $325.9{ }^{\circ} \mathrm{C}$ (Lit. 310; ${ }^{42} 327^{43}$ ). ${ }^{1} \mathrm{H}$ NMR (300 MHz, $\mathrm{CDCl}_{3}$ ): $\delta$ $8.19(\mathrm{~d}, J=7.8 \mathrm{~Hz}, 4 \mathrm{H}), 7.82(\mathrm{~s}, 4 \mathrm{H}), 7.57(\mathrm{~d}, J=8.2 \mathrm{~Hz}, 4 \mathrm{H}), 7.47$ $(\mathrm{td}, J=7.3,1.2 \mathrm{~Hz}, 4 \mathrm{H}), 7.33(\mathrm{td}, J=7.3,1.2 \mathrm{~Hz}, 4 \mathrm{H}) .{ }^{13} \mathrm{C}\left\{{ }^{1} \mathrm{H}\right\}$ NMR $\left(75.5 \mathrm{MHz}, \mathrm{CDCl}_{3}\right): \delta 140.75,136.67,128.38,126.14$, 123.57, 120.47, 120.29, 109.77. Anal calcd for: $\mathrm{C}_{30} \mathrm{H}_{20} \mathrm{~N}_{2}: \mathrm{C}$, 88.21; H, 4.93; N, 6.86. Found: C, 88.00; H, 4.95; N, 6.73\%.

\section{1,4-Bis(3,6-di-tert-butylcarbazol-9-yl)benzene (1b)}

The title compound was synthesized using essentially the same approach as 1a. A mixture of $\mathbf{9 b}(1.00 \mathrm{~g}, 3.6 \mathrm{mmol})$, 1,4-dibromobenzene $(0.42 \mathrm{~g}, 1.79 \mathrm{mmol})$, copper powder $(0.23 \mathrm{~g}, 3.6$ $\mathrm{mmol}), \mathrm{K}_{2} \mathrm{CO}_{3}(1.5 \mathrm{~g}, 10.8 \mathrm{mmol})$ and 18-crown-6 (0.47 g, 1.79 $\mathrm{mmol})$ were suspended in 1,2-dichlorobenzene $(30 \mathrm{~mL})$ and purged with argon for $30 \mathrm{~min}$. The reaction was refluxed for $7 \mathrm{~d}$ under an argon atmosphere. The crude mixture was filtered and the residue was washed with $\mathrm{CHCl}_{3}(3 \times 10 \mathrm{~mL})$. The filtrate was evaporated under reduced pressure and the residue was purified by column chromatography using hexane- $\mathrm{CH}_{2} \mathrm{Cl}_{2}(20: 1)$ as eluent. The brown solid was then recrystallized from toluene-ethanol to obtain $\mathbf{1 b}$ as white solid $(0.55 \mathrm{~g}, 48 \%), \mathrm{mp}$ (determined by DSC) $373{ }^{\circ} \mathrm{C}$ (no literature melting point has been reported for this compound). ${ }^{1} \mathrm{H} \mathrm{NMR}\left(300 \mathrm{MHz}, \mathrm{CDCl}_{3}\right): \delta$ $8.18(\mathrm{~d}, J=0.9 \mathrm{~Hz}, 4 \mathrm{H}), 7.77(\mathrm{~s}, 4 \mathrm{H}), 7.55-7.52(\mathrm{dd}, J=8.7$, $0.9 \mathrm{~Hz}, 4 \mathrm{H}), 7.51-7.50(\mathrm{~d}, J=8.7 \mathrm{~Hz}, 4 \mathrm{H}), 1.49$ (s, 36H). ${ }^{13} \mathrm{C}\left\{{ }^{1} \mathrm{H}\right\}$ NMR (75.5 MHz, $\mathrm{CDCl}_{3}$ ): $\delta 143.12,139.12,136.66,128.22,127.8$, 123.74, 123.48, 109.20, 34.77, 32.02. Anal calcd for: $\mathrm{C}_{46} \mathrm{H}_{52} \mathrm{~N}_{2}$ : C, 87.29; H, 8.28; N, 4.43. Found: C, 87.01; H, 8.40; N, 4.47\%.

\section{4,4'-Bis(carbazol-9-yl)biphenyl (2a)}

The title compound was synthesized according to a general literature procedure. ${ }^{42}$ A mixture of carbazole $(2.50 \mathrm{~g}, 15.0$ mmol), 1,8-diiodobiphenyl (2.00 g, $4.93 \mathrm{mmol})$, copper powder (0.94 g, $15 \mathrm{mmol}$ ), $\mathrm{K}_{2} \mathrm{CO}_{3}(5.45 \mathrm{~g}, 39.4 \mathrm{mmol}$ ) and 18-crown-6 $(1.30 \mathrm{~g}, 4.92 \mathrm{mmol})$ were suspended in 1,2-dichlorobenzene $(50 \mathrm{~mL})$ and purged with argon for $30 \mathrm{~min}$. The reaction mixture was refluxed for $7 \mathrm{~d}$ under argon atmosphere. The crude mixture 
was filtered and the filtrate was cooled in fridge; the solid formed was collected and recrystallized twice from ethyl acetate to obtain 2a as light brown needles (1.3 g, 47\%), mp (determined by DSC) $282.2{ }^{\circ} \mathrm{C}$ (Lit. $\left.290 ;{ }^{42} 281^{44}\right) .{ }^{1} \mathrm{H}$ NMR (300 MHz, $\mathrm{CDCl}_{3}$ ): $\delta$ $8.19(\mathrm{~d}, J=7.2 \mathrm{~Hz}, 4 \mathrm{H}), 7.94$ (m overlapping, 4H), 7.74 (m overlapping, $4 \mathrm{H}), 7.54(\mathrm{~d}, J=7.2 \mathrm{~Hz}, 4 \mathrm{H}), 7.48-7.43(\mathrm{td}, J=6.9$, $1.2 \mathrm{~Hz}, 4 \mathrm{H}), 7.35-7.31(\mathrm{td}, J=6.9,1.2 \mathrm{~Hz}, 4 \mathrm{H}) .{ }^{13} \mathrm{C}\left\{{ }^{1} \mathrm{H}\right\} \mathrm{NMR}$ $\left(75.5 \mathrm{MHz}, \mathrm{CDCl}_{3}\right): \delta 140.80,139.29,137.24,128.53,127.49$, 126.2, 123.48, 120.38, 120.07, 109.82. Anal calcd for $\mathrm{C}_{36} \mathrm{H}_{24} \mathrm{~N}_{2}$ : C, 89.23; H, 4.99; N, 5.78. Found: C, 89.07; H, 4.80; N, 5.79\%.

\section{4,4'-Bis(di-tert-butylcarbazol-9-yl)biphenyl (2b)}

A mixture of 3,6-di-tert-butyl-9H-carbazole $9 b(2.47 \mathrm{~g}, 8.84$ mmol), 1,8-diiodobiphenyl (1.20 g, $2.95 \mathrm{mmol})$, copper powder $(0.56 \mathrm{~g}, 8.8 \mathrm{mmol}), \mathrm{K}_{2} \mathrm{CO}_{3}(3.26 \mathrm{~g}, 0.0236 \mathrm{~mol})$ and 18-crown-6 $(0.78 \mathrm{~g}, 3.0 \mathrm{mmol})$ were suspended in 1,2-dichlorobenzene $(30 \mathrm{~mL})$ and purged with argon for $30 \mathrm{~min}$. The reaction was refluxed for $7 \mathrm{~d}$ under argon atmosphere. The crude mixture was filtered and the filtrate was left in the fridge for $2 \mathrm{~d}$; the resulting solid was collected and recrystallized from ethyl acetate to obtain $\mathbf{2 b}$ as white solid ( $0.80 \mathrm{~g}, 30 \%$ ), mp (determined by DSC) $438.0{ }^{\circ} \mathrm{C}$ (no literature melting point has been reported for this compound). ${ }^{1} \mathrm{H}$ NMR (300 $\left.\mathrm{MHz}, \mathrm{CDCl}_{3}\right): \delta 8.17$ $(\mathrm{d}, J=1.5 \mathrm{~Hz}, 4 \mathrm{H}), 7.91-7.89$ (d, $J=8.4 \mathrm{~Hz}, 4 \mathrm{H}), 7.71$ (d, $J=$ $8.4 \mathrm{~Hz}, 4 \mathrm{H}), 7.52-7.49(\mathrm{dd}, J=1.5 \mathrm{~Hz}, J=8.7 \mathrm{~Hz}, 4 \mathrm{H}), 7.46(\mathrm{~d}, J=$ $8.7 \mathrm{~Hz}, 4 \mathrm{H}) .{ }^{13} \mathrm{C}\left\{{ }^{1} \mathrm{H}\right\} \mathrm{NMR}\left(75.5 \mathrm{MHz}, \mathrm{CDCl}_{3}\right): \delta 142.98,139.16$, 138.83, 137.65, 128.37, 127.05, 123.68, 123.46, 116.31, 109.28, 34.76, 32.05. Anal calcd for $\mathrm{C}_{52} \mathrm{H}_{56} \mathrm{~N}_{2}$ : C, 88.09; H, 7.96; N, 3.95. Found: C, 87.93; H, 7.97; N, 3.96\%.

\section{2,7-Bis(carbazol-9-yl)-4,5,9,10-tetrahydropyrene (3a)}

A $10 \mathrm{~mL}$ microwave tube was charged with carbazole $(289 \mathrm{mg}$, $1.73 \mathrm{mmol}$ ), 2,7-dibromo-4,5,9,10-tetrahydropyrene 7 (300 mg, $0.824 \mathrm{mmol}$ ), and a magnetic stir bar. In a glove box under nitrogen atmosphere, tris(dibenzylideneacetone)dipalla$\operatorname{dium}(0)$ (60 mg, $0.066 \mathrm{mmol}$ ), tri-tert-butylphosphine (165 mg, $0.568 \mathrm{mmol}$ ), sodium tert-butoxide (353 $\mathrm{mg}, 3.67 \mathrm{mmol}$ ), and dry toluene $(6 \mathrm{~mL})$ were added. The tube was sealed under nitrogen and the reaction was conducted in the microwave under standard control conditions (power: $180 \mathrm{~W}$; max temp: $125{ }^{\circ} \mathrm{C}$; run time: $2 \mathrm{~min}$; hold time: $60 \mathrm{~min}$; pressure: $120 \mathrm{psi}$ ). The reaction mixture was then poured into ice-water $(100 \mathrm{~mL})$ and extracted with chloroform $(3 \times 50 \mathrm{~mL})$; the extracts were successively washed with water and brine. The solution was dried over anhydrous $\mathrm{MgSO}_{4}$ and was run through a short bed of silica. The solvent was removed under reduced pressure and the resulting solid was recrystallized from toluene-ethanol to yield 3a as white solid (393 $\mathrm{mg}, 55 \%$ ), mp (determined by DSC) $394.2{ }^{\circ} \mathrm{C} .{ }^{1} \mathrm{H}$ NMR $\left(300 \mathrm{MHz}, \mathrm{CDCl}_{3}\right): \delta 8.19-8.16(\mathrm{~d}, J=7.8 \mathrm{~Hz}$, $4 \mathrm{H}), 7.54-7.51(\mathrm{~d}, J=8.1 \mathrm{~Hz}, 4 \mathrm{H}), 7.54-7.45(\mathrm{td}, J=7.2,1.2 \mathrm{~Hz}$, $4 \mathrm{H}), 7.34(\mathrm{~s}, 4 \mathrm{H}), 7.33-7.29(\mathrm{td}, J=7.2,1.2 \mathrm{~Hz}, 4 \mathrm{H}), 3.08(\mathrm{~s}, 8 \mathrm{H})$. ${ }^{13} \mathrm{C}\left\{{ }^{1} \mathrm{H}\right\} \mathrm{NMR}\left(75.5 \mathrm{MHz}, \mathrm{CDCl}_{3}\right): \delta$ 140.91, 137.05, 136.50, 129.46, 125.89, 124.50, 123.36, 120.32, 119.86, 110.00, 28.34 . HRMS-EI $(\mathrm{m} / \mathrm{z})$ : $[\mathrm{M}]^{+}$: calcd for $\mathrm{C}_{40} \mathrm{H}_{28} \mathrm{~N}_{2}, 536.2252$; found, 536.2234. Anal calcd for $\mathrm{C}_{40} \mathrm{H}_{28} \mathrm{~N}_{2}$ : C, 89.52; H, 5.26; N, 5.22. Found: C, 89.37; H, 5.23; N, 5.22\%.

\section{2,7-Bis(3,6-di-tert-butylcarbazol-9-yl)-4,5,9,10- tetrahydropyrene (3b)}

A $10 \mathrm{~mL}$ microwave tube was charged with 3,6-di-tert-butyl-9Hcarbazole 9b (484 mg, $1.73 \mathrm{mmol}$ ), 2,7-dibromo-4,5,9,10-tetrahydropyrene 7 (300 mg, $0.824 \mathrm{mmol}$ ), and a magnetic stir bar. In a glove box under nitrogen atmosphere, tris(dibenzylideneacetone)dipalladium(0) (60 mg, $0.066 \mathrm{mmol})$, tri-tert-butylphosphine (165 mg, $0.568 \mathrm{mmol}$ ), sodium tert-butoxide (353 mg, 3.67 $\mathrm{mmol})$, and dry toluene $(6 \mathrm{~mL})$ were added. The tube was sealed under nitrogen and the reaction was conducted in the microwave under standard control conditions (power: $180 \mathrm{~W}$; $\max$ temp: $125{ }^{\circ} \mathrm{C}$; run time: $2 \mathrm{~min}$; hold time: $60 \mathrm{~min}$; pressure: 120 psi). The reaction mixture was then poured into ice-water (100 $\mathrm{mL})$ and extracted with chloroform $(3 \times 50 \mathrm{~mL})$; the extracts were successively washed with water and brine. The solution was dried over anhydrous $\mathrm{MgSO}_{4}$ and was run through a short bed of silica. The solvent was removed under reduced pressure and the resulting solid was recrystallized from toluene-ethanol to yield $3 \mathrm{~b}$ as white solid (405 mg, 65\%). ${ }^{1} \mathrm{H}$ NMR $(300 \mathrm{MHz}$, $\left.\mathrm{CDCl}_{3}\right): \delta 8.16(\mathrm{~d}, J=0.9 \mathrm{~Hz}, 4 \mathrm{H}), 7.52-7.48(\mathrm{dd}, J=8.7,1.8 \mathrm{~Hz}$, $4 \mathrm{H}), 7.47-7.43(\mathrm{~d}, J=9.0 \mathrm{~Hz}, 4 \mathrm{H}), 7.32(\mathrm{~s}, 4 \mathrm{H}), 3.05$ (s, 8H), 1.49 (s, 36H). ${ }^{13} \mathrm{C}\left\{{ }^{1} \mathrm{H}\right\}$ NMR (75.5 MHz, $\left.\mathrm{CDCl}_{3}\right): \delta$ 142.74, 139.27, 136.84, 129.10, 129.03, 124.08, 123.54, 123.32, 116.21, 109.41, 34.75, 32.04, 28.37. HRMS-EI $(\mathrm{m} / \mathrm{z})$ : $[\mathrm{M}]^{+}$: calcd for $\mathrm{C}_{56} \mathrm{H}_{60} \mathrm{~N}_{2}$, 760.4757; found, 760.4723. Anal calcd for $\mathrm{C}_{56} \mathrm{H}_{60} \mathrm{~N}_{2}$ : C, 88.37; $\mathrm{H}$, 7.95; N, 3.68. Found: C, 88.18; H, 7.80; N, 3.67\%.

\section{2,7-Bis(carbazol-9-yl)pyrene (4a)}

A $10 \mathrm{~mL}$ microwave tube was charged with carbazole (196 mg, 1.17 $\mathrm{mmol}$ ), 2,7-dibromopyrene 8 (200 $\mathrm{mg}, 0.555 \mathrm{mmol})$, and a magnetic stir bar. In a glove box under nitrogen atmosphere, tris(dibenzylideneacetone)dipalladium(0) (40 mg, $0.044 \mathrm{mmol}$ ), tri-tert-butylphosphine $(110 \mathrm{mg}, 0.379 \mathrm{mmol})$, sodium tert-butoxide (235 mg, $2.44 \mathrm{mmol}$ ), and dry toluene (6 mL) were added. The tube was sealed under nitrogen and the reaction was conducted in the microwave under power control conditions (power: $180 \mathrm{~W}$; max temp: $125{ }^{\circ} \mathrm{C}$; run time: $2 \mathrm{~min}$; hold time: $60 \mathrm{~min}$; pressure: $120 \mathrm{psi})$. The reaction mixture was then poured into ice-water $(100$ $\mathrm{mL})$ and extracted with chloroform $(3 \times 50 \mathrm{~mL})$; the extract were then washed with water and brine, dried over anhydrous $\mathrm{MgSO}_{4}$, and run through a short bed of silica. The solvent was removed under reduced pressure and the resulting solid was recrystallized twice from toluene-ethanol to yield $4 \mathrm{a}$ as white solid $(185 \mathrm{mg}$, $63 \%$ ) mp (determined by DSC) $364.6{ }^{\circ} \mathrm{C} .{ }^{1} \mathrm{H}$ NMR (300 MHz, $\left.\mathrm{CDCl}_{3}\right): \delta 8.46(\mathrm{~s}, 4 \mathrm{H}), 8.26-8.23$ (m overlapping, $\left.4 \mathrm{H}\right), 8.23(\mathrm{~s}$ overlapping, $4 \mathrm{H}), 7.58-7.55(\mathrm{~d}, J=7.8 \mathrm{~Hz}, 4 \mathrm{H}), 7.49-7.44(\mathrm{td}, J=$ 6.9, $1.2 \mathrm{~Hz}, 4 \mathrm{H}), 7.39-7.34(\mathrm{td}, J=7.8,1.2 \mathrm{~Hz}, 4 \mathrm{H}) .{ }^{13} \mathrm{C}\left\{{ }^{1} \mathrm{H}\right\} \mathrm{NMR}$ $\left(75.5 \mathrm{MHz}, \mathrm{CDCl}_{3}\right): \delta 141.41,135.76,132.57,128.14,126.14,123.76$, 123.57, 120.48, 120.26, 109.63, 105.00. HRMS-EI (m/z): $[\mathrm{M}]^{+}$: calcd for $\mathrm{C}_{40} \mathrm{H}_{24} \mathrm{~N}_{2}$, 532.1939; found, 532.1936. Anal calcd for $\mathrm{C}_{40} \mathrm{H}_{24} \mathrm{~N}_{2}$ : C, 90.20; H, 4.54; N, 5.26. Found: C, 89.84; H, 4.47; N, 5.27\%.

\section{2,7-Bis(3,6-di-tert-butylcarbazol-9-yl)pyrene (4b)}

A $10 \mathrm{~mL}$ microwave tube was charged with 3,6-di-tert-butyl-9Hcarbazole 9b (326 mg, $1.17 \mathrm{mmol}$ ), 2,7-dibromopyrene 8 
(200 mg, $0.555 \mathrm{mmol}$ ), and a magnetic stir bar. In a glove box under nitrogen atmosphere, tris(dibenzylideneacetone)dipalladium(0) (40 mg, $0.044 \mathrm{mmol}$ ), tri-tert-butylphosphine (110 mg, $0.379 \mathrm{mmol}$ ), sodium tert-butoxide (235 $\mathrm{mg}, 2.44 \mathrm{mmol}$ ), and dry toluene $(6 \mathrm{~mL})$ were added. The tube was sealed under nitrogen and the reaction was conducted in the microwave under power control conditions (power: $180 \mathrm{~W}$; $\max$ temp: $125{ }^{\circ} \mathrm{C}$; run time: $2 \mathrm{~min}$; hold time: $60 \mathrm{~min}$; pressure: $120 \mathrm{psi}$ ). The reaction mixture was then poured into ice-water $(100 \mathrm{~mL})$ and extracted with chloroform $(3 \times 50 \mathrm{~mL})$; the extracts were washed with water and brine, dried over anhydrous $\mathrm{MgSO}_{4}$, and run through a short bed of silica. The solvent was removed under reduced pressure and the resulting solid was recrystallized from toluene-ethanol to yield $\mathbf{4 b}$ as white solid (339 $\mathrm{mg}$, 81\%). ${ }^{1} \mathrm{H}$ NMR (300 MHz, $\left.\mathrm{CDCl}_{3}\right): \delta 8.43(\mathrm{~s}, 4 \mathrm{H}), 8.23(\mathrm{~s}, 4 \mathrm{H})$, $8.19(\mathrm{~s}, 4 \mathrm{H}), 7.52(\mathrm{~s}, 4 \mathrm{H}), 7.51(\mathrm{~s}, 4 \mathrm{H}), 1.51(\mathrm{~s}, 36 \mathrm{H}) .{ }^{13} \mathrm{C}\left\{{ }^{1} \mathrm{H}\right\} \mathrm{NMR}$ $\left(75.5 \mathrm{MHz}, \mathrm{CDCl}_{3}\right): \delta 143.19,139.74,136.17,132.46,128.05$, 123.78, 123.56, 123.37, 116.40, 109.02, 105.00, 34.81, 32.04. HRMS-EI $(\mathrm{m} / \mathrm{z}):[\mathrm{M}]^{+}$: calcd for $\mathrm{C}_{56} \mathrm{H}_{56} \mathrm{~N}_{2}, 756.4444$; found, 756.4426. Anal calcd for $\mathrm{C}_{56} \mathrm{H}_{56} \mathrm{~N}_{2}$ : C, 88.84; $\mathrm{H}, 7.46 ; \mathrm{N}, 3.70$. Found: C, 88.68; H, 7.59; N, 3.63\%.

\section{Photophysical studies}

The photophysical studies of compounds 1-4 were performed using 1-5 $\mu \mathrm{M}$ solutions of each compound prepared in different solvents. The procedure involved the measurement of 1-2 mg of each compound in a vial for the preparation of a stock solution (1 $\mathrm{mM})$ in DCM. Dilutions were done in another vial to obtain $100 \mu \mathrm{M}$ solutions from which $40-200 \mu \mathrm{L}$ were taken, placed in different vials, and left to dry. Different solvents were then added to each vial $(4 \mathrm{~mL})$ to obtain $1-5 \mu \mathrm{M}$ solutions. A JASCO V-570 UV-NIR spectrophotometer was used for measurements of the absorption spectra, and the fluorescence measurements were done using a Jobin-Yvon-Horiba Fluorolog III spectrofluorimeter. The excitation source was a $100 \mathrm{~W}$ xenon lamp and the slit width was fixed at $5 \mathrm{~nm}$ for all measurements, while the excitations were done at 330 or $320 \mathrm{~nm}$. In order to find the fluorescence lifetime of compounds (1-4), a Jobin-Yvon-Horiba FluorologIII spectrofluorimeter was used with a pulsed diode laser $(282 \mathrm{~nm})$. The decay data were analyzed using Data Analysis software to fit decays to single or double exponential with $\chi^{2}<3$.

\section{X-Ray structure determination}

X-ray diffraction experiments were carried out with a Bruker SMART APEX II CCD diffractometer, using Mo K $\alpha$ radiation $(\lambda=$ $0.71073 \AA$ ) at $100 \mathrm{~K}$; details of the solution and refinement and given in Table S1 (ESI $\dagger$ ), while cif files are available from the Cambridge Crystallographic Data Center where the crystal structures of $\mathbf{1 a}, \mathbf{2 b}, \mathbf{3 a}$, and $\mathbf{4 b}$ have been deposited and allocated the deposition numbers CCDC 899423, 899424, 899425, and 899426 , respectively. The raw data frames were integrated with the SAINT+ program using narrow-frame algorithm. ${ }^{45}$ Absorption corrections were applied using the semi-empirical method of the SADABS program. ${ }^{46}$ The structures were solved by direct methods and refined using the Bruker SHELXTL programs suite ${ }^{47}$ by full-matrix least-squares methods on $F^{2}$ with SHELXL-97 in anisotropic approximation for all nonhydrogen atoms. Compound 1a was found to crystallize in the orthorhombic space group $\mathrm{Pbca}$, with an entire molecule in the asymmetric unit, whereas crystals of $\mathbf{2 b}, 3 \mathbf{a}$, and $\mathbf{4 b}$ belong to the monoclinic space group $P 2_{1} / c$ with half of the molecule in the asymmetric unit. In $\mathbf{2 b}$ disorder was modeled for the bridging six-membered ring over two positions with partial occupancies of $0.53(3)$ and $0.47(3)$. In 3a disorder was modeled for the $C_{s p}{ }^{3}$ atoms in the tetrahydropyrene core over two positions with partial occupancies of $0.63(8)$ and $0.37(8)$. All $\mathrm{H}$ atoms were placed in idealized positions and refined with constrained $\mathrm{C}-\mathrm{H}$ distances and $U_{\text {iso }}(\mathrm{H})$ values set to $1.2 U_{\text {eq }}$ or $1.5 U_{\text {eq }}$ (for methyl group) of the attached $\mathrm{C}$ atom.

\section{Organic light-emitting devices and electroluminescence- measurements}

Devices were fabricated using a standard sandwich assembly to investigate these new materials as the active layer in OLEDs: indium tin oxide (ITO)/poly(3,4-ethylenedioxythiophene)-polystyrenesulfonic acid (Baytron P VPAI 4083) (PEDOT:PSS)/3a, 3b, 4a, 4b/1,3,5-tris(1-phenyl-1H-2-benzimidazole) (TPBi)/Ca/Al. ITO-covered glass substrates were mechanically cleaned by the use of acetone and isopropyl alcohol. Afterwards the substrates were subjected to various supersonic treatments in deionized water, toluene, and isopropanol. A dry cleaning step in oxygen plasma finished the cleaning procedure. On top of the ITOsubstrates a layer of PEDOT:PSS was applied via spin-coating under ambient conditions and dried under dynamic vacuum according to the specifications. Layers of $\mathbf{3 a}$ and $\mathbf{4 a}$ with a thickness of $80 \mathrm{~nm}$ were evaporated at an evaporation rate of $0.5 \AA \mathrm{s}^{-1}$ from a resistively heated crucible under dynamic vacuum in an evaporation chamber having an initial base pressure $<1.0 \times 10^{-6}$ mbar. Film thicknesses were monitored using a quartz-crystal microbalance. Compounds $\mathbf{3 b}$ and $\mathbf{4 b}$ were spin-coated from $5 \mathrm{mg} \mathrm{mL} \mathrm{mL}^{-1}$ THF solutions in inert atmosphere and dried at $80{ }^{\circ} \mathrm{C}$ for $2 \mathrm{~h}$ in vacuum. The resulting layer thickness amounted to $75 \mathrm{~nm}$. The cathode materials (TPBi, Ca, Al) were deposited in an evaporation chamber under high vacuum $\left(p<1.0 \times 10^{-6}\right.$ mbar $)$ TPBi (10 nm) was evaporated uniformly onto the substrate as an electron transport layer, $\mathrm{Ca}(10 \mathrm{~nm})$ and $\mathrm{Al}(100 \mathrm{~nm})$ were deposited through a shadow mask thus forming multiple devices with a device-area of $9 \mathrm{~mm}^{2}$ on a single substrate.

Electroluminescence (EL) spectra were acquired using an ORIEL spectrometer with an attached calibrated charge-coupled device (CCD) camera. Current-luminance-voltage $(I-L-V)$ characteristics were recorded in a customized setup using a Keithley 2612A source measure unit for recording the $I-V$ characteristics while the luminance was measured by a Keithley 6485 Picoammeter using a photodiode calibrated by a Konica-Minolta LS-100 Luminancemeter.

\section{Quantum-chemical studies}

The ground states and radical-cation states of $\mathbf{1 b} \mathbf{b} \mathbf{4 b}$ were calculated at the density functional theory (DFT) level by 
employing the global hybrid B3LYP functional ${ }^{48-51}$ in conjunction with a 6-31G(d,p) basis set. ${ }^{52,53}$ The low-lying singlet excited states were evaluated using the neutral ground-state geometries via time-dependent density functional theory (TDDFT) with the B3LYP functional and the same basis set. All calculations were performed using the Gaussian09 (Revision A.02) software suite. ${ }^{54}$

\section{Results and discussion}

\section{Synthesis}

Compounds 1-4 were synthesized from Ullmann or BuchwaldHartwig coupling of the appropriate carbazole to the dibromo/ diiodo derivatives of the bridging groups. The bridging groups required for the synthesis of compounds 3 and 4 were synthesized from pyrene, 5, as shown in Scheme 1, according to literature procedures: pyrene was first activated using RANEY ${ }^{\circledR}$ nickel and then hydrogenated at 40 psi for 3 days in the presence of $\mathrm{Pd} / \mathrm{C}$ to yield 4,5,9,10-tetrahydropyrene, $6^{38}$ 2,7Dibromo-4,5,9,10-tetrahydropyrene, 7, was obtained through the bromination of 6 using bromine in acetic acid. ${ }^{39}$ Oxidation of 7 using bromine and $\mathrm{CS}_{2}$ at room temperature yielded 2,7dibromopyrene, $\mathbf{8 .}^{\mathbf{4 0}}$ Compound 8 cannot be obtained from direct bromination of $\mathbf{5}$, which gives $1,3,6,8$-tetrabromopyrene ${ }^{55}$ although recently a transition-metal catalyzed $\mathrm{C}-\mathrm{H}$ activation approach to the direct 2,7-diborylation of $\mathbf{5}$ has been reported. ${ }^{\mathbf{5 6}}$ 3,6-Di-tert-butyl-9H-carbazole, 9b, was synthesized from $9 \mathrm{H}^{-}$ carbazole, 9a, using a previously described $\mathrm{ZnCl}_{2}$-mediated Friedel-Crafts alkylation with 2-chloro-2-methylpropane in nitromethane (Scheme 2). ${ }^{41}$

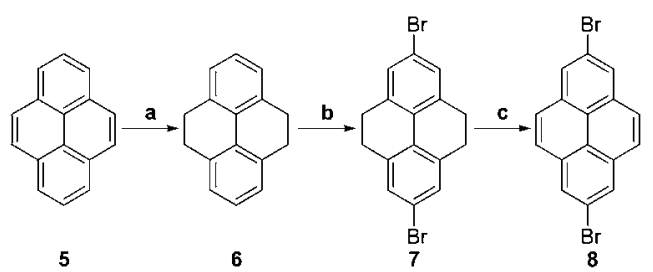

Scheme 1 Synthesis of 2,7-dibromo-4,5,9,10-tetrahydropyrene and 2,7-dibromopyrene. (a) (1) RANEY® nickel; (2) Pd/C, $\mathrm{H}_{2}$ (40 psi); (b) $\mathrm{AcOH}, \mathrm{Br}_{2}, \mathrm{NaOH}$; (c) $\mathrm{CS}_{2}, \mathrm{Br}_{2}$.

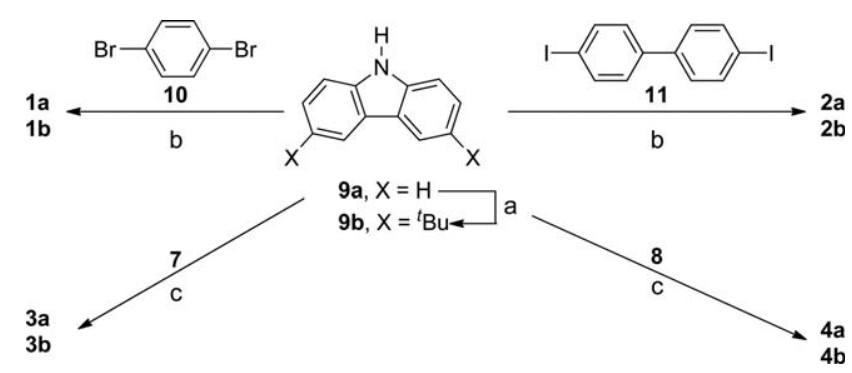

Scheme 2 Synthesis of bis(carbazolyl) derivatives of benzene, biphenyl, tetrahydropyrene, and pyrene. (a) ${ }^{t} \mathrm{BuCl}$, nitromethane, $\mathrm{ZnCl}_{2}$; (b) $\mathrm{Cu}, \mathrm{K}_{2} \mathrm{CO}_{3}, 18$-crown6, 1,2-dichlorobenzene (reflux, 1 week); (c) $\mathrm{Pd}_{2}(\mathrm{dba})_{3}, \mathrm{P}^{t} \mathrm{Bu}_{3}, \mathrm{NaO}{ }^{t} \mathrm{Bu}$, toluene, 120 psi, 1 h (microwave).
The well-known compounds $\mathbf{1 a}$ and $\mathbf{2 a}$ were obtained essentially as described in the literature, ${ }^{\mathbf{4 2}}$ using Ullmann condensation reactions of 9a with 1,4-dibromobenzene, 10, and 4,4'-diiodobiphenyl, 11, respectively (Scheme 2). Their tertbutyl-substituted analogues, $\mathbf{1 b}$ and $\mathbf{2 b}$, have been reported: $\mathbf{1 b}$ has been obtained from the Ullmann reaction of $\mathbf{9 b}$ and 1,4-diiodobenzene (although no experimental details and characterizing data were reported), ${ }^{57}$ while $\mathbf{2 b}$ was obtained by Friedel-Crafts alkylation of $\mathbf{2 a} .{ }^{9}$ We synthesized $\mathbf{1 b}$ and $\mathbf{2 b}$ from 9b and the appropriate dibromoarene/diiodoarene bridging groups using the same Ullmann conditions used for $\mathbf{1 a}$ and $\mathbf{2 a}$.

The Ullmann approach requires stoichiometric quantities of copper reagent and, typically, high temperatures $\left(>200{ }^{\circ} \mathrm{C}\right)$ and long reaction times, and often gives only moderate yields; an alternative is the Buchwald-Hartwig palladium-catalyzed $\mathrm{C}-\mathrm{N}$ coupling reaction. ${ }^{58,59}$ We obtained 3 and 4 in moderate to good yield from reaction of the appropriate dibromopyrene and carbazole derivatives (Scheme 2), using the tris(dibenzylideneacetone)dipalladium(0)/tri-tert-butylphosphine catalyst system, as described for $N$-arylation of carbazole in ref. 60 , but using microwave irradiation to accelerate the reaction (with a maximum temperature of $125^{\circ} \mathrm{C}$, run time of $2 \mathrm{~min}$, hold time of $60 \mathrm{~min}$, pressure of $120 \mathrm{psi}$, and power of $180 \mathrm{~W}$ ).

\section{Crystal and molecular structures}

Single crystals of 1,4-bis(carbazol-9-yl)benzene (1a), 4,4'-bis(3,6di-tert-butylcarbazol-9-yl)biphenyl (2b), 2,7-bis(carbazol-9-yl)4,5,9,10-tetrahydropyrene (3a), and 2,7-bis(3,6-di-tert-butylcarbazol-9-yl)pyrene (4b) were obtained by crystallization from dichloromethane-ethyl acetate solution and their structures were determined using X-ray diffraction; the structure of 2a has previously been reported, ${ }^{\mathbf{6 1}}$ while suitable crystals were not obtained for the remaining materials. Details of the solutions and refinements are listed in Table $\mathrm{S} 1 \dagger$ and the molecular structures are shown in Fig. 2. The molecules are held together in the crystal by van der Waals interactions and no short intermolecular contacts or close $\pi$-stacking interactions were found (see ESI $\dagger$ for packing diagrams). Density functional theory (DFT) optimizations of the ground-state structures of $\mathbf{1 b}$, $\mathbf{2 b}, \mathbf{3 b}$, and $\mathbf{4 b}$ were carried out for direct comparison; selected DFT (B3LYP/6-31G(d,p))-calculated geometric parameters are given in Table $\mathrm{S} 1 \dagger$ and compared with the crystallographic parameters.

In the "gas-phase" DFT calculations, the biphenyl unit of $\mathbf{2 b}$ is characterized by a twist angle of $37^{\circ}$, the $\mathrm{CH}_{2} \mathrm{CH}_{2}$ "bridges" of $3 \mathbf{b}$ lead to a lower twist of $17^{\circ}$, while only in the pyrene derivative 4b do the " $\mathrm{CH}=\mathrm{CH}$ " bridges lead to complete planarization of the biphenyl portion of the bridge. Molecules of $\mathbf{2 b}, \mathbf{3 a}$, and $\mathbf{4 b}$ are located on crystallographic inversion centers in their crystals, meaning that the biphenyl portions of the bridging moieties are apparently planar, as is the case in the previously reported structure of $\mathbf{2 a},{ }^{61}$ although this is likely an artifact of disorder, as in the case of biphenyl itself, ${ }^{62}$ precluding a meaningful comparison of experimental and DFT bridge geometries. In both the crystallographically determined and DFT structures, the carbazole moieties are significantly twisted 
a)

b)

西

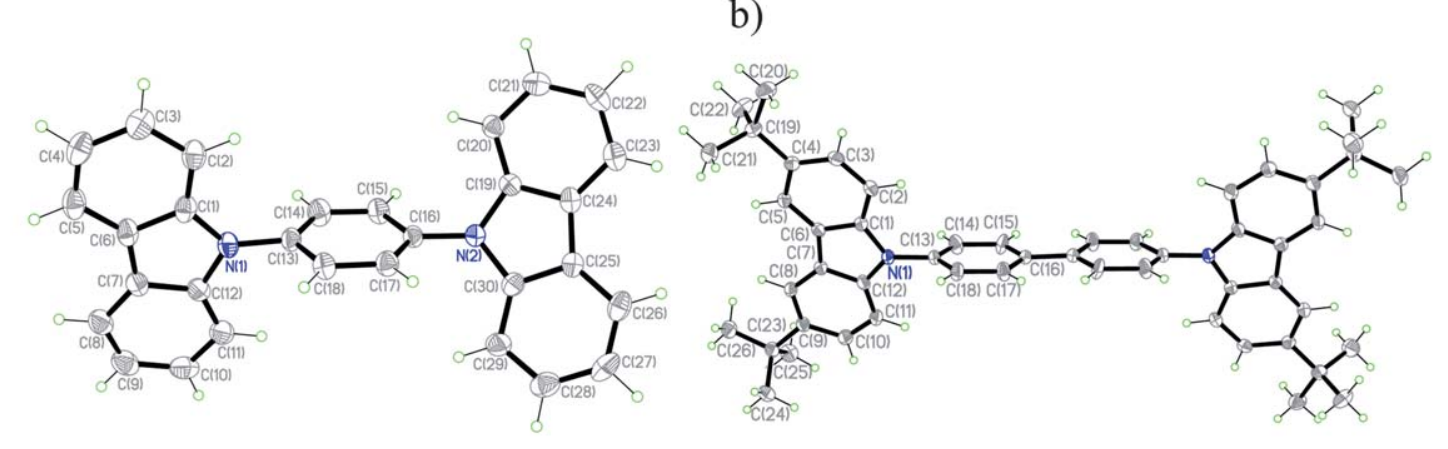

c)

d)

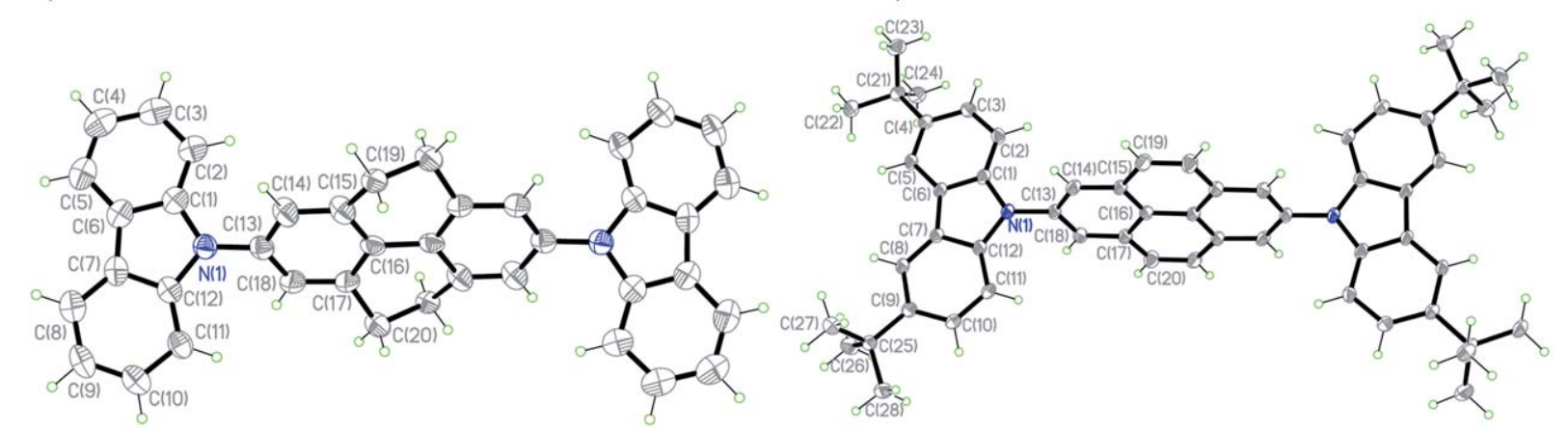

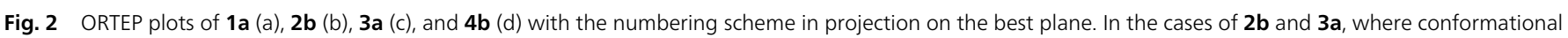

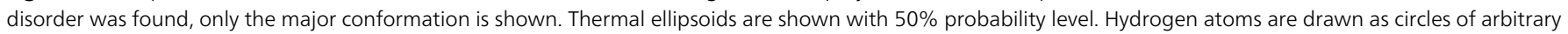
small radii for clarity.

from coplanarity with the adjacent bridging group, consistent with the expected effects of steric interactions and with other structures of $N$-aryl carbazole derivatives; however, in the calculated structures, the angles between these two planes are all close to $53^{\circ}$, while there is considerable variation in the angles found in the crystal structures (see Table S2 $†$ ). Although the nitrogen atoms in the DFT structures are all fully planarized, the coordination geometries of the carbazole nitrogen atoms in all four crystal structures are not perfectly planar: the extent of pyramidalization is, however, well within the range of values that have been observed for other $N$-aryl carbazoles. ${ }^{63-66}$ These geometric differences may indicate relatively shallow potential energy surfaces with respect to these distortions so that minor crystal packing effects can lead to variations.

On the other hand, there is good general agreement between crystallographically determined and calculated bond lengths, suggesting that DFT describes the electronic structure of these molecules well (see below). For example, the bridging $\mathrm{N}$ (carbazole)-C(aryl bridge) bonds are in the range of 1.422(4)$1.428(4) \AA(1.417-1.419 \AA$ ̊ DFT), agreeing well with bond lengths reported in literature. ${ }^{63-67}$ The C-C bond lengths of the DFT and $\mathrm{X}$-ray structures follow similar patterns. Notably, the calculations indicate that the central $\mathrm{C}-\mathrm{C}$ bond of the biphenyl portion of the bridge shortens from biphenyl (1.483 $\AA$ ) to tetrahydropyrene $(1.473 \AA)$ to pyrene $(1.424 \AA$ ), consistent (allowing for the low precision of the $2 \mathbf{b}$ structure) with the trends in the corresponding crystallographic bond lengths (1.489(2), 1.464(12), $1.470(4)$, and $1.422(3) \AA$ for $2 \mathbf{a},{ }^{61} \mathbf{2 b}, 3 \mathbf{a}$, and $\mathbf{4 b}$, respectively). While the small difference in the $\mathrm{C}-\mathrm{C}$ bond lengths of the tetrahydropyrene and biphenyl bridges likely reflects constraints imposed by the $\mathrm{CH}_{2} \mathrm{CH}_{2}$ groups, the much shorter central bond in the pyrene system indicates that there is a significant change in electronic structure of the bridge (see below for a discussion of the molecular orbitals) and that the simplistic representation of pyrene as a biphenyl moiety planarized by $\mathrm{CH}=\mathrm{CH}$ groups is inadequate.

\section{Absorption and fluorescence studies}

Fig. 3a and b show the absorption and fluorescence spectra respectively of the carbazole and 3,6-di-tert-butylcarbazole derivatives (1-4) in DMF (see ESI $\dagger$ for spectra acquired in different solvents). In all cases, the absorption spectra showed a common sharp peak at around $295 \mathrm{~nm}$ and broader weaker features in the range $310-340 \mathrm{~nm}$. In the case of 2a, these have been described as carbazole-localized transitions and transitions between more extensively delocalized $\pi$ and $\pi^{*}$ orbitals, respectively ${ }^{68}$ although carbazole itself also shows a weak transition at $c a .330 \mathrm{~nm}$ in addition to a strong absorption at $c a$. $290 \mathrm{~nm} .{ }^{69}$ The absorption maxima, emission maxima, and Stokes shift of each compound are summarized in Table 1. 3,6tert-Butyl substitution of the carbazole moieties results in small red-shifts in absorption ( $c a .0-80 \mathrm{meV}$ ) and fluorescence ( $c a .70-$ $135 \mathrm{meV}$ ) maxima compared to their unsubstituted analogues, consistent with a previous comparison of $2 \mathbf{a}$ and $2 \mathbf{b} .{ }^{9}$ The pyrene derivatives have the lowest energy emission maxima (429 
a)

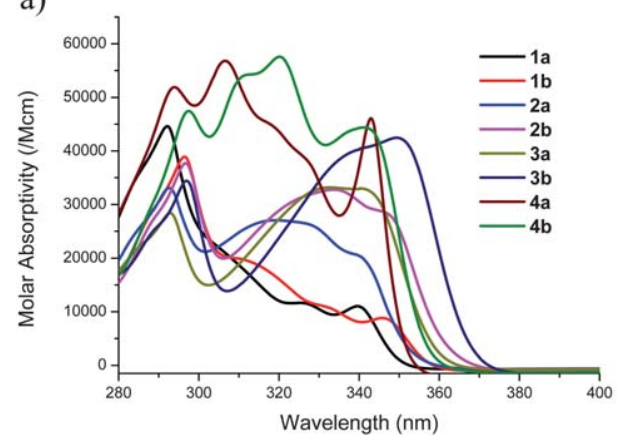

b)

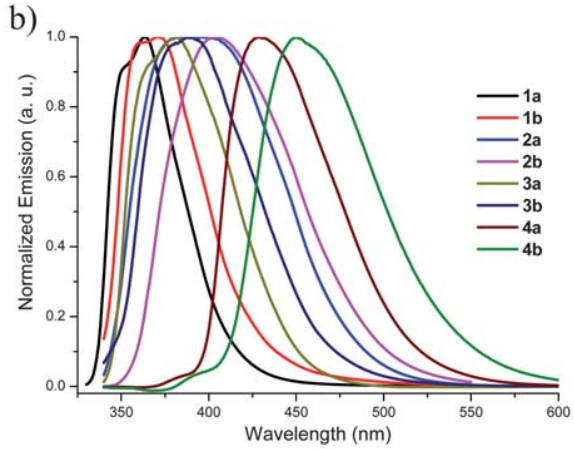

Fig. 3 Absorption (a) and normalized emission (b) spectra of compounds 1-4 in DMF.

Table 1 Absorption and emission data for 1-4 in $\mathrm{DMF}^{a}$

\begin{tabular}{|c|c|c|c|c|c|}
\hline Compound & $\begin{array}{l}\lambda_{\mathrm{abs}}^{\max }(\mathrm{nm}) \\
\left(\varepsilon\left(\mathrm{M}^{-1} \mathrm{~cm}^{-1}\right)\right)\end{array}$ & $\begin{array}{l}\lambda_{\mathrm{em}}^{\max } \\
(\mathrm{nm})\end{array}$ & $\begin{array}{l}\text { Stokes shift } \\
\left(\mathrm{cm}^{-1}\right)\end{array}$ & $\Phi_{\mathrm{f}}{ }^{b}$ & $\tau_{\mathrm{fl}} / \mathrm{ns}^{c}$ \\
\hline $1 \mathbf{a}$ & $340(11000)$ & 363 & 1864 & 0.46 & 6.56 \\
\hline $1 b$ & $346(8800)$ & 371 & 1948 & 0.24 & $\begin{array}{l}13.2(53 \%), \\
5.73(47 \%)^{d}\end{array}$ \\
\hline $2 a$ & $340(20500)$ & 387 & 3572 & 0.42 & 2.50 \\
\hline $2 b$ & $347(28400)$ & 404 & 4066 & 0.15 & 3.05 \\
\hline $3 \mathbf{a}$ & $341(33000)$ & 381 & 3079 & 0.49 & 1.95 \\
\hline $3 \mathbf{b}$ & $349(42500)$ & 389 & 2946 & 0.69 & $\begin{array}{l}2.03(56 \%), \\
0.12(44 \%)^{d}\end{array}$ \\
\hline $4 a$ & $343(46000)$ & 429 & 5844 & 0.44 & $\begin{array}{l}2.78(1 \%), \\
24.7(99 \%)^{d}\end{array}$ \\
\hline $4 b$ & $341(44400)$ & 450 & 7103 & 0.42 & 18.9 \\
\hline
\end{tabular}

${ }^{a}$ Optical data in other solvents are presented in Tables S5 and S6 in the ESI. ${ }^{b}$ Fluorescence quantum yield. ${ }^{c}$ Fluorescence lifetime. ${ }^{d}$ Biexponential fit; the relative contribution of the two components is also indicated.

and $450 \mathrm{~nm}$ for $\mathbf{4 a}$ and $\mathbf{4 b}$, respectively) and exhibit the greatest Stokes shifts (between the lowest energy observed absorption maximum and the fluorescence maximum) of any of the compounds examined, although another weaker emission feature is present at $c a$. $380-390 \mathrm{~nm}$; as discussed below, this is

Table 2 Time-dependent DFT (TDDFT) determination of selected vertical transition energies $\left(E_{\text {vert }}, \mathrm{eV}\right)$, wavelengths $\left(\lambda_{\text {vert }}, \mathrm{nm}\right)$, transition dipole moments ( $\mu_{\mathrm{ge}}$, Debye), and electronic configurations as determined at the B3LYP/6-31G(d,p) level of theory

\begin{tabular}{|c|c|c|c|c|c|}
\hline Compound & & $\begin{array}{l}E_{\text {vert }} \\
(\mathrm{eV})\end{array}$ & $\begin{array}{l}\lambda_{\text {vert }} \\
(\mathrm{nm})\end{array}$ & $\begin{array}{l}\mu_{\text {ge }} \\
\text { (Debye) }\end{array}$ & Electronic configuration \\
\hline $1 \mathbf{b}$ & $\mathrm{S}_{0} \rightarrow \mathrm{S}_{1}$ & 3.78 & 328 & 6.07 & $\begin{array}{l}\text { HOMO } \rightarrow \text { LUMO }(69 \%) ; \\
\text { HOMO } \rightarrow \text { LUMO+2 }(29 \%)\end{array}$ \\
\hline $2 \mathbf{b}$ & $\mathrm{S}_{0} \rightarrow \mathrm{S}_{1}$ & 3.46 & 359 & 7.24 & HOMO $\rightarrow$ LUMO (98\%) \\
\hline $3 \mathbf{b}$ & $\mathrm{S}_{0} \rightarrow \mathrm{S}_{1}$ & 3.33 & 372 & 7.55 & HOMO $\rightarrow$ LUMO (98\%) \\
\hline \multirow[t]{3}{*}{$4 b$} & $\mathrm{~S}_{0} \rightarrow \mathrm{S}_{1}$ & 2.78 & 446 & 0.87 & HOMO $\rightarrow$ LUMO (98\%) \\
\hline & $\mathrm{S}_{0} \rightarrow \mathrm{S}_{5}$ & 3.50 & 354 & 2.62 & $\begin{array}{l}\text { HOMO } \rightarrow \text { LUMO+1 }(75 \%) ; \\
\text { HOMO-4 } \rightarrow \text { LUMO }(23 \%)\end{array}$ \\
\hline & $\mathrm{S}_{0} \rightarrow \mathrm{S}_{7}$ & 3.73 & 332 & 9.69 & $\begin{array}{l}\text { HOMO-4 } \rightarrow \text { LUMO }(64 \%) ; \\
\text { HOMO } \rightarrow \text { LUMO+1 }(22 \%) ; \\
\text { HOMO-7 } \rightarrow \text { LUMO+1 (5\%); } \\
\text { HOMO } \rightarrow \text { LUMO+3 (3\%) }\end{array}$ \\
\hline
\end{tabular}

consistent with the lowest energy absorption maximum not corresponding to $\mathrm{S}_{0} \rightarrow \mathrm{S}_{1}$ in the pyrene compounds.

Table 2 provides the vertical transition energies (and wavelengths), transition dipoles, and electronic configurations of the lowest-lying excited states with appreciable oscillator strength as determined at the TDDFT B3LYP/6-31G(d,p) level of theory. The calculated maxima, though slightly red-shifted with respect to experiment, ${ }^{70}$ agree well with the empirical trends. For $\mathbf{1 b}$ through $\mathbf{3 b}$, the first vertical transition with appreciable oscillator strength is the $S_{0} \rightarrow S_{1}$ transition; in each case these are well-described as HOMO $\rightarrow$ LUMO excitations (although in $\mathbf{1 b}$, the HOMO $\rightarrow$ LUMO+2 excitation also contributes to the transition). Depictions of the molecular orbitals involved in the transitions are located in the ESI; $†$ in the case of $\mathbf{1 b}$, the HOMO and LUMO are fully delocalized across both carbazole units and the central phenylene bridge. In the case of $\mathbf{2 b}$ and $\mathbf{3 b}$, the HOMO has a similar delocalized character, while the LUMO is mainly localized on the central biphenyl portion with only modest extension on the carbazole (consistent with previous reports of the frontier orbitals of $\mathbf{2 a}$ and $2 \mathbf{b}^{\mathbf{9}}$ ). Thus, the lowestlying transitions are indeed well-described as $\pi-\pi^{*}$ transitions, as previously suggested for $\mathbf{2 a},{ }^{\mathbf{6 8}}$ although they have significant carbazole-to-bridge charge-transfer character.

The picture differs for $\mathbf{4 b}$, where the $S_{0} \rightarrow S_{1}$ transition, which largely corresponds to excitation from a carbazole-localized HOMO to a pyrene-localized LUMO (Fig. 4), has negligible transition dipole. This pyrene-localized LUMO has very little wavefunction distribution, as expected, on the 2- and 7-positions that connect the carbazole end groups to the pyrene center - in direct contrast with the phenyl (1b) and biphenyl(-like) bridges ( $2 \mathbf{b}$ and $\mathbf{3 b}$ ) of the other systems - therefore limiting the wavefunction overlap of the ground and excited states. Consistent with the small transition dipole moments linking these states, the fluorescence lifetimes of $\mathbf{4 a}$ and $\mathbf{4 b}$ are longer than those observed for the other compounds in most solvents (see Table 2 and ESI $\dagger$ ). Two higher-lying transitions $\left(\mathrm{S}_{0} \rightarrow \mathrm{S}_{5}\right.$ and $\mathrm{S}_{0} \rightarrow \mathrm{S}_{7}$ ) with mixed HOMO $\rightarrow$ LUMO+1 and HOMO-4 $\rightarrow$ LUMO character are the first transitions with any appreciable transition dipole; they presumably correspond to the lowestenergy experimentally observed absorption maximum. Assuming the main observed emission peak to be the $S_{0} \rightarrow S_{1}$ emission, the large Stokes shifts seen for $\mathbf{4 a}$ and $\mathbf{4 b}$ are, 

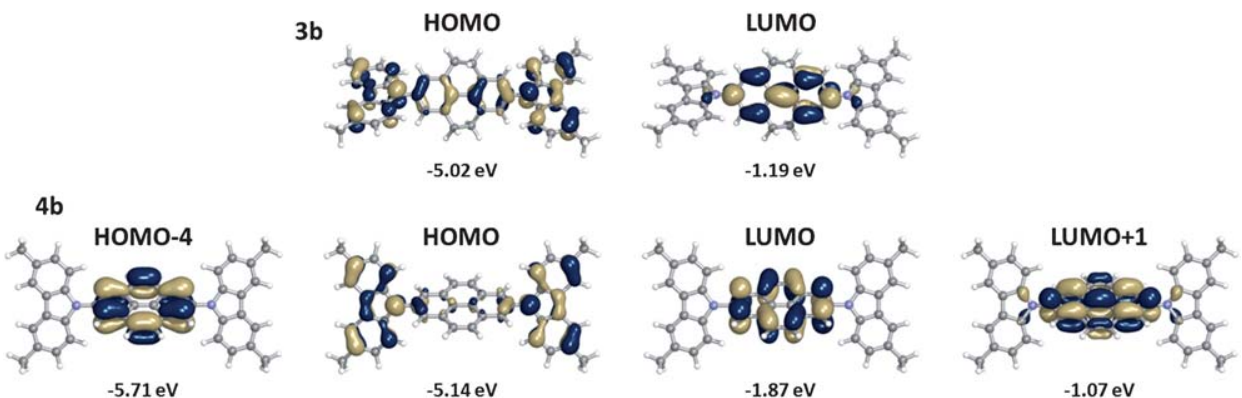

Fig. 4 Illustrations of the frontier molecular orbitals and molecular orbital energies of $\mathbf{3} \mathbf{b}$ and $\mathbf{4} \mathbf{b}$ evaluated at the B3LYP/6-31 G(d,p) level.

therefore, easily understood (the small emission peak at $c a$. $370-380 \mathrm{~nm}$ perhaps occurring from one of the higher lying states with more significant coupling to the ground state). The LUMO+1 is mainly pyrene-localized, closely resembling the LUMO+1 of an isolated pyrene, ${ }^{56,71-80}$ while the HOMO-4 is located on the pyrene unit and corresponds with the HOMO of pyrene itself (see Fig. 4). The most important contributor to $\mathrm{S}_{0} \rightarrow \mathrm{S}_{5}$ is the HOMO $\rightarrow$ LUMO+1 excitation, indicating that this transition has significant quadrupolar carbazole-to-pyrene charge-transfer character and some similarity to $S_{0} \rightarrow S_{1}$ for the other compounds. The HOMO- $4 \rightarrow$ LUMO excitation is the most important contributor to the $\mathrm{S}_{0} \rightarrow \mathrm{S}_{7}$ transition; this transition is primarily a pyrene-localized transition, closely corresponding to the $S_{0} \rightarrow S_{2}$ transition of pyrene..$^{56}$

Fluorescence quantum yields of 1-4 were determined in different solvents (Table S5†). It was observed that solvent polarity affected the overall fluorescence quantum yield. In general, higher fluorescence quantum yields were observed in non-polar solvents (i.e. cyclohexane and hexane) and mediumpolarity solvents (i.e. DCM and THF), while lower fluorescence quantum yields were recorded in polar solvents such as acetonitrile, methanol and ethanol. Solvent dependence was also manifested in the fluorescence lifetime $\left(\tau_{\mathrm{f}}\right){ }^{81}$ Data for the eight carbazole derivatives were fit to mono- or biexponential decays. Generally, there was no clear trend among the lifetime values in different solvents. However, the lowest lifetime ( $\tau_{1}$ or $\tau_{\text {avg }}$ ) was obtained in hexane for compounds 1a, 2a, 2b, 3a, 3b, $\mathbf{4 a}, \mathbf{4 b}$, while $\mathbf{1} \mathbf{b}$ was an exception with the lowest $\tau_{\text {avg }}$ value being found in ethanol (see ESI $\dagger$ ). Importantly, the recorded lifetimes for compounds $\mathbf{1}(\mathbf{a}, \mathbf{b}), \mathbf{2}(\mathbf{a}, \mathbf{b}), \mathbf{3}(\mathbf{a}, \mathbf{b})$ were less than $10 \mathrm{~ns}$, while the pyrene-based compounds ( $\mathbf{4 a}$ and $\mathbf{4 b}$ ) exhibited higher lifetimes in most solvents with values up to 22 ns. Nonetheless, these lifetimes fall considerably short of those found for pyrene itself (ca. $400 \mathrm{~ns}) .^{82}$ It should be noted that despite the small calculated $\mathrm{S}_{0} \rightarrow \mathrm{S}_{1}$ transition dipoles and the long fluorescence lifetimes for $\mathbf{4 a}$ and $\mathbf{4 b}$, the solution fluorescence quantum yields are still moderately large (up to $56 \%$, see Table $\mathrm{S} 5 \dagger$ ) and comparable to those found for 1-3. The observed biexponential decays for some compounds (1a only in methanol, $\mathbf{1 b}$ (except in acetonitrile), $\mathbf{3 b}$ and $\mathbf{4 b}$ in all the solvents) may be attributed to various origins of the radiative transitions such as intramolecular twisting in the excited state or charge transfer states. ${ }^{83}$ The radiative $\left(k_{\mathrm{r}}\right)$ and non-radiative $\left(k_{\mathrm{nr}}\right)$ rate constants of 1-4 in various solvents are summarized in Table S6. $†$

\section{Redox properties}

The solution electrochemistry of $\mathbf{1 a - 4 a}$ and $\mathbf{1 b} \mathbf{\mathbf { b }} \mathbf{4} \mathbf{b}$ was investigated using cyclic voltammetry (CV) using $0.1 \mathrm{M}^{n} \mathrm{Bu}_{4} \mathrm{NPF}_{6}$ in dichloromethane as electrolyte. Compounds $\mathbf{1 a}-\mathbf{4 a}$ all undergo irreversible oxidation, consistent with previous reports for other carbazole derivatives without 3,6-substitution, including $\mathbf{2 a} \mathbf{a}^{61}$ this irreversibility is attributed to coupling of carbazole radical cations through those positions, in which the spin density is relatively high. ${ }^{30-32}$ In contrast, $\mathbf{1 b} \mathbf{b} \mathbf{- 4}$ all undergo two sequential reversible oxidation processes indicating that these coupling reactions are effectively suppressed; this qualitative difference is shown for the example of $4 \mathbf{a} v s$. $\mathbf{4 b}$ in Fig. 5, while the other CVs are shown in the ESI. $\nmid$ Although irreversible oxidations are observed for many carbazoles with useful solidstate hole-transport properties, such as $\mathrm{PVK}^{84}$ and $2 \mathrm{a},{ }^{61}$ reversible electrochemistry might be expected to lead to more stable device behavior due to fewer decomposition reactions of the charge-carrying species.

The first oxidation potentials, $E_{1 / 2}^{+/ 0}$, of the reversibly oxidized tert-butyl derivatives $\mathbf{1 b}-\mathbf{4 b}$ materials vary by only $c a$. $0.1 \mathrm{~V}$ within the series; DFT-calculated values of ionization potential (IP) also show relatively minor variation. For $\mathbf{2 b}, \mathbf{3} \mathbf{b}$, and $\mathbf{4 b}$, the minor variations in the DFT $\triangle \mathrm{SCF}$ estimates of gas-phase vertical and adiabatic IPs, or of the IPs according to Koopmans' theorem, correlate very well with those in $E_{1 / 2}^{+/ 0}$; the correlation is

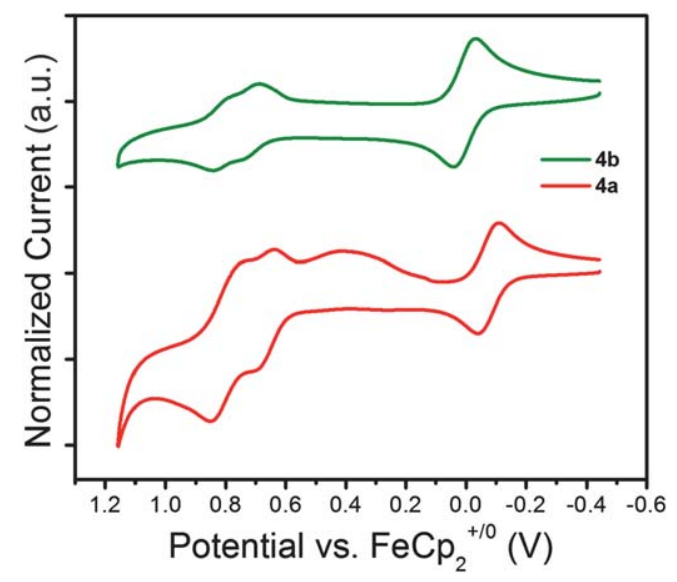

Fig. 5 Cyclic Voltammograms $\left(50 \mathrm{mV} \mathrm{s}^{-1}\right)$ for 1,4-bis(carbazol-9-yl)pyrene (4a) and 1,4-bis(3,6-di-tert-butylcarbazol-9-yl)pyrene (4b) with ferrocene as an internal standard in $\mathrm{CH}_{2} \mathrm{Cl}_{2}-0.1 \mathrm{M}^{n} \mathrm{Bu}_{4} \mathrm{NPF}_{6}$. 


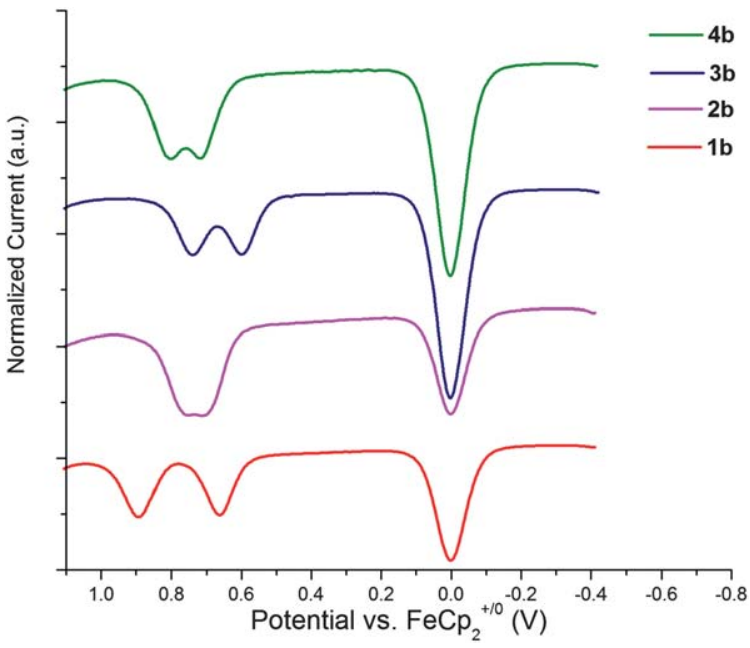

Fig. 6 Oxidative differential pulse voltammograms $\left(20 \mathrm{mV} \mathrm{s}^{-1} ; 50 \mathrm{mV}\right.$ pulse width) for bis(3,6-di-tert-butylcarbazol-9-yl) derivatives in $\mathrm{CH}_{2} \mathrm{Cl}_{2}-0.1 \mathrm{M}$ ${ }^{n} \mathrm{Bu}_{4} \mathrm{NPF}_{6}$; the feature at $0 \mathrm{~V}$ corresponds to oxidation of the ferrocene internal standard.

less good for $\mathbf{1 b}$; as in the previously reported (more pronounced) discrepancy between trends in gas-phase IP values and electrochemical potentials for bis(dimethylamino)benzene, biphenyl, and tolane derivatives, this is likely to be due to a greater solvation effect on the electrochemical potentials for the species with the smaller bridge. ${ }^{85}$ The similarity of redox potentials and calculated IPs within the series is consistent with the largely carbazole-localized nature of the HOMO in all cases, while some of the variation can be attributed to the varying bridge contributions; in particular, $\mathbf{4 b}$ is significantly less readily ionized than $\mathbf{3} \mathbf{b}$ owing to the destabilizing interaction of the carbazole and bridge-based orbitals in the latter system, while there is barely any pyrene contribution to the HOMO of $\mathbf{4 b}$.

In the case of the reversibly oxidized 3,6-di(tert-butyl)carbazole derivatives, $\mathbf{1 b}-\mathbf{4 b}$, differential pulse voltammetry (DPV) ${ }^{86}$ was also used to better separate the two oxidation features and better determine the separation $\Delta E_{1 / 2}=E_{1 / 2}^{2+/+}-E_{1 / 2}^{+/ 0}$. As shown in Fig. 6 and Table 3, there is considerable variation in the separation between the two oxidations. The largest separation is seen for $\mathbf{1} \mathbf{b}$; this is expected given the shorter bridge between the two carbazole redox centers (for example, greater values of $\Delta E_{1 / 2}$ are seen for bis(di- $p$-anisylamino)benzene and bis(dimethylamino)benzene than for their respective biphenyl-bridged analogues), ${ }^{85,87}$ which gives rise to increased delocalization, and, in the case of a class-II monocation, increased electrostatic interactions, stabilizing the monocation. The variation between the remaining compounds shows no clear trend; however, values of $\Delta E_{1 / 2}$ are known to depend on a number of additional factors, ${ }^{88}$ some of which are perhaps in competition with one another in the present series.

The solid-state IPs of the compounds were estimated to be in the range 5.4-5.6 eV according to the empirically established approximate relation, $\mathrm{IP}_{\mathrm{s}}=e E_{1 / 2}^{+/ 0}+4.8 \mathrm{eV}$, where $e$ is the electronic charge and where the potential is relative to ferrocenium/ ferrocene. The value of $5.5 \mathrm{eV}$ estimated for $\mathbf{2 b}$ is close to a value of $5.7 \mathrm{eV}$ directly measured by UV photoelectron spectroscopy for $\mathbf{2 b}$ (and also for 2a). ${ }^{9,89}$ Estimates of the electron affinity (EA) in the solid state, obtained using the crude approximation, $\mathrm{EA}_{\mathrm{s}}=\mathrm{IP}_{\mathrm{s}}-E_{\mathrm{g}}^{\mathrm{opt}}$, where $E_{\mathrm{g}}^{\mathrm{opt}}$ is an estimate of the energy of the first singlet excited state, are also given in Table 3. In general, this approach will lead to overestimates of $\mathrm{EA}_{\mathrm{s}}$ due to the effects of exciton binding energy. Moreover, as discussed in the previous section, the onset of strong absorption correspond to the $S_{0} \rightarrow S_{1}$ transition for $\mathbf{1 b}-\mathbf{3} \mathbf{b}$, but $S_{0} \rightarrow S_{5}$ for $\mathbf{4} \mathbf{b}$, meaning that this approach is unlikely to even afford meaningful trends in $\mathrm{EA}_{\mathrm{s}}$ in the present series. Indeed the estimated $\mathrm{EA}_{\mathrm{s}}$ values are all similar, while the DFT estimate of the EA obtained from Koopmans' theorem for $\mathbf{4 b}$ is much larger than that of $\mathbf{2 b}$ or $\mathbf{3 b}$ (Table 3). The trends in $\mathrm{EA}_{\mathrm{KT}}$ reflect the fact that the $\pi$-system of the bridge increases in size from $\mathbf{1 b}$ to $2 \mathbf{b} / \mathbf{3 b}$ and then, again, to $\mathbf{4 b}$; in addition, the LUMO in $\mathbf{4 b}$ is strongly pyrene localized and less destabilized by contributions from the carbazole portions of the molecule than that of $\mathbf{1 b} \mathbf{b} \mathbf{3 b}$.

The DFT geometries of $\mathbf{1} \mathbf{b}^{+}-\mathbf{4} \mathbf{b}^{+}$were examined to gain further insight into the redox properties of these species. In principle, cations such as these might be either class-II (unsymmetrical with charge largely localized around one of the nitrogen atoms) or III (delocalized) mixed-valence species..$^{90}$ Electron self-interaction errors in DFT often leads to artificially delocalized solutions; ${ }^{91}$ therefore, while delocalized class-III structures are obtained from the DFT calculations and this result is similar to

Table 3 Oxidation potentials of 3,6-di-tert-butylcarbazole derivatives vs. ferrocenium/ferrocene in $\mathrm{CH}_{2} \mathrm{Cl}_{2}-0.1 \mathrm{M}^{n} \mathrm{Bu}_{4} \mathrm{NPF}_{6}$, electrochemically based estimates of ionization potentials and electron affinities, and computational estimates of the gas phase ionization potentials and electron affinities at the B3LYP/6-31G(d,p) level of theory

\begin{tabular}{|c|c|c|c|c|c|c|c|c|c|c|c|c|}
\hline \multirow[b]{2}{*}{ Cpd } & \multicolumn{7}{|c|}{ Experiment } & \multicolumn{5}{|l|}{ Theory } \\
\hline & $E_{1 / 2}^{+/ 0 a}(\mathrm{~V})$ & $E_{1 / 2}^{+2 /+a}(\mathrm{~V})$ & $\Delta E_{1 / 2}(\mathrm{mV})$ & $\lambda_{\text {onset }^{b}}^{b}(\mathrm{~nm})$ & $E_{\mathrm{g}}^{\mathrm{opt} b}(\mathrm{eV})$ & $\mathrm{IP}_{\mathrm{s}}^{c}(\mathrm{eV})$ & $\mathrm{EA}_{\mathrm{s}}^{d}(\mathrm{eV})$ & $\operatorname{IP}_{\text {vert }}^{e}(\mathrm{eV})$ & $\mathrm{IP}_{\mathrm{adi}}^{e}(\mathrm{eV})$ & $\mathrm{IP}_{\mathrm{KT}}^{f}(\mathrm{eV})$ & $\mathrm{EA}_{\mathrm{KT}}^{f}(\mathrm{eV})$ & $\begin{array}{l}\mathrm{IP}_{\mathrm{KT}}- \\
\mathrm{EA}_{\mathrm{KT}}(\mathrm{eV})\end{array}$ \\
\hline $1 \mathrm{~b}$ & +0.66 & +0.89 & 237 & 358 & 3.46 & 5.5 & 2.0 & 6.21 & 6.13 & 5.12 & 0.73 & 4.39 \\
\hline $2 \mathbf{b}$ & +0.71 & +0.75 & 76 & 363 & 3.42 & 5.5 & 2.1 & 6.10 & 6.05 & 5.13 & 1.15 & 3.97 \\
\hline $3 \mathbf{b}$ & +0.60 & +0.74 & 148 & 370 & 3.35 & 5.4 & 2.1 & 5.99 & 5.92 & 5.02 & 1.19 & 3.83 \\
\hline $4 b$ & +0.72 & +0.80 & 104 & 358 & 3.46 & 5.5 & 2.1 & 6.11 & 6.06 & 5.14 & 1.87 & 3.27 \\
\hline
\end{tabular}

${ }^{a}$ Potentials obtained from the DPV measurements. ${ }^{b}$ Onset of optical absorption. ${ }^{c}$ Estimated solid-state IP obtained according to IP $=e E_{1 / 2}^{+/ 0}+4.8$ eV. ${ }^{d}$ Estimated of the solid-state IP obtained according to EA $=\mathrm{IP}-E_{\mathrm{g}}^{\mathrm{opt}}$; see text for caveats. ${ }^{e} \Delta \mathrm{SCF}$ values of vertical and adiabatic ionization energies for isolated molecules. ${ }^{f}$ DFT gas-phase values estimated using Koopmans' theorem, i.e. $\mathrm{IP}_{\mathrm{KT}}=-E_{\mathrm{HOMO}}$ and $\mathrm{EA}_{\mathrm{KT}}=-E_{\mathrm{LUMO}}$. 
what is experimentally established for bis(diarylamino)biphenyl radical cations, ${ }^{92}$ it is possible that some or all of these radical cations may in fact exhibit localized structures, in which case adiabatic IPs, geometric changes, and reorganization energies will differ somewhat from those given in Table S4. $†$ The largest geometric changes occur in the vicinity of the carbazole-bridge linkages. The $\mathrm{N}$ (carbazole)-C(aryl bridge) bonds shorten by 0.01-0.02 $\AA$, with the bond length change being largest for the smallest example, $\mathbf{1 b}$. The induced strain of the alkyl linkage in the bridge of $3 \mathbf{b}$ induces a slightly larger change to the $\mathrm{N}-\mathrm{C}$ bond versus the unconstrained biphenyl bridge of $2 \mathbf{b}$, while the $\mathrm{N}-\mathrm{C}$ bond change is smallest for $\mathbf{4 b}$, where there is relatively little $\mathrm{N}-$ $\mathrm{C}$ (bridge) antibonding character in the HOMO. A considerable reduction in the torsion angle between the carbazole units and the neighboring aryl rings of the bridge also occurs on oxidation, again with the largest change occurring for $1 \mathbf{b}$ ( $11^{\circ}$ reduction), an intermediate change for $\mathbf{3 b}\left(9^{\circ}\right)$, and the smallest for $\mathbf{2 b}$ and $\mathbf{4 b}$ $\left(\right.$ ca. $\left.6^{\circ}\right)$. The twist angle between the two benzene rings of the biphenyl ring of $\mathbf{2} \mathbf{b}$ also decreases (by $7^{\circ}$ ) on oxidation, but does not significantly change in the case of $\mathbf{3} \mathbf{b}$ (where the constraints of the alkyl bridges lead to a lower twist in the neutral geometry, as discussed above). The planarization of the biphenyl bridge of $2 \mathbf{b}^{+}$is reminiscent of previously reported computational and crystallographic studies of bis(diarylamino)biphenyl derivatives and their radical cations..$^{92,93}$

The varying degrees of geometric modifications on oxidation lead to notable differences in the neutral/radical cation intramolecular reorganization energy, which, according to Marcus theory, ${ }^{94}$ is related to the barrier to hole transport. The smaller 1b, which undergoes the largest changes to the geometric structure on oxidation, has the largest intramolecular reorganization energy $(176 \mathrm{meV})$. The alkyl bond constraints in $\mathbf{3 b}$, interestingly, lead to a considerably larger intramolecular reorganization energy $(150 \mathrm{meV})$ than that found in $\mathbf{2 b}$ $(112 \mathrm{meV})$. This difference is qualitatively similar to that between bis(diarylamino)biphenyl and fluorene derivatives. ${ }^{95,96}$ The intramolecular reorganization energy of $\mathbf{4 b}(90 \mathrm{meV})$ is the smallest and is comparable with that of the high hole-mobility material pentacene $(98 \mathrm{meV}) .{ }^{97}$ All of these intramolecular organization energies are smaller than those estimated for many prototypical hole-transport materials, including TPD $(290 \mathrm{meV})^{95}$ and sexithiophene $(300 \mathrm{meV}){ }^{98}$

\section{Organic light-emitting devices}

To investigate the electroluminescent (EL) properties of compounds $3 \mathbf{a}, \mathbf{3} \mathbf{b}, \mathbf{4 a}$ and $\mathbf{4 b}$, OLEDs were assembled in a standard sandwich geometry: ITO/PEDOT:PSS/[carbazole derivative]/TPBi/Ca/Al; 3a and $\mathbf{4 a}$ were deposited by evaporation, while $\mathbf{3 b}$ and $\mathbf{4 b}$ were spin-cast. 1,3,5-Tris(1-phenyl$1 H$-benzo[ $d]$ imidazol-2-yl)benzene (TPBi) is widely used as a hole-blocking/electron-transporting material, ${ }^{8}$ and in the current devices was deposited by evaporation to facilitate electron injection into the active layer. All devices give deep blue EL, with maxima in the range $422-435 \mathrm{~nm}$, suggesting that emission occurs primarily from the carbazole-material layer; TPBi films show a fluorescence maximum at $383 \mathrm{~nm} .{ }^{99}$

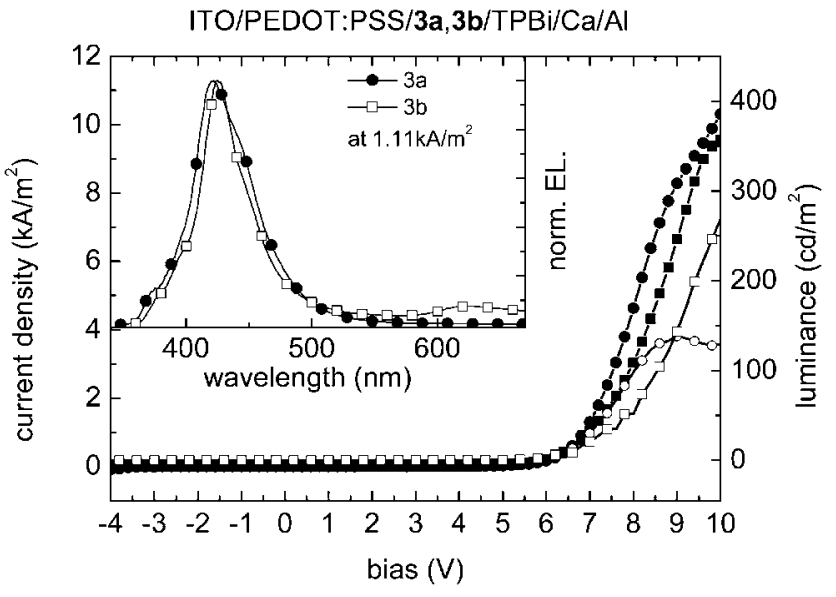

Fig. 7 Current density (3a: line with filled circles; $3 \mathbf{b}$ : line with filled squares)/ luminance (3a: line with open circles; $\mathbf{3} \mathbf{b}$ : line with open squares) as a function of the bias voltage of ITO/PEDOT:PSS/3a, 3b/TPBi/Ca/Al devices. Inset: electroluminescence emission spectra at a current density of $1.11 \mathrm{kA} \mathrm{m}^{-2}$.

Fig. 7 depicts the current density-voltage-luminance $(J-V-L)$ characteristics of devices using $\mathbf{3 a}$ and $\mathbf{3 b}$, respectively, as lightemitting layers. The tetrahydropyrene-based OLEDs gave maximum luminance values of $138 \mathrm{~cd} \mathrm{~m}^{-2}$ at $9 \mathrm{~V}$ for $3 \mathbf{a}$ and $361 \mathrm{~cd} \mathrm{~m}^{-2}$ at $10.8 \mathrm{~V}$ for $3 \mathbf{b}$. The onset voltages of 5.3 and $5.5 \mathrm{~V}$ for $\mathbf{3 a}$ and $\mathbf{3 b}$, respectively, are rather high and indicate either imbalanced charge injection or transport within the devices. Consequently the maximum device efficiencies remained low ( 0.02 and $0.07 \mathrm{~cd} \mathrm{~A}^{-1}$ for $\mathbf{3 a}$ and $\mathbf{3 b}$, respectively). Devices using 3a as the light-emitting layer show an EL peak maximum at $422 \mathrm{~nm}$ and a weak shoulder around $375 \mathrm{~nm}$. The spectra correspond to Commission Internationale de l'Eclairage 1931 (CIE1931) coordinates of $x=0.159$ and $y=0.046$, corresponding to a deep blue emission. For $\mathbf{3 b}$ devices, a slightly narrower EL emission peak was observed in a similar region to that seen for 3a devices (EL maximum at $425 \mathrm{~nm}$ ), but a weak and slightly structured emission is also seen in the red spectral region at around $620 \mathrm{~nm}$; similar EL features in PVK films have been attributed to electrophosphorescent emission. ${ }^{100}$ The overall spectrum corresponds to CIE1931 $x=0.193$ and $y=0.078$, which is slightly red-shifted compared to the EL-emission of 3a, but still located in the deep-blue region of the visible spectrum.

Fig. 8 shows the $J-V-L$ characteristics of analogous devices in which $\mathbf{4 a}$ and $\mathbf{4 b}$ are used as emitters. Maximum luminance values of $1076 \mathrm{~cd} \mathrm{~m}^{-2}$ were obtained for the $4 a$ device at $7.0 \mathrm{~V}$ and $316 \mathrm{~cd} \mathrm{~m}^{-2}$ at $7.6 \mathrm{~V}$ for $\mathbf{4 b}$, respectively. The onset voltages of $4.0 \mathrm{~V}(\mathbf{4 a})$ and $4.2 \mathrm{~V}(\mathbf{4 b})$ are somewhat smaller than when tetrahydropyrene-bridged molecules $\mathbf{3 a}$ and $\mathbf{3 b}$ were used as the active layer, perhaps due to more facile electron injection into the pyrene molecules (see values of $\mathrm{EA}_{\mathrm{KT}}$ in Table 3). However, the overall device efficiencies of $0.16 \mathrm{~cd} \mathrm{~A}^{-1}$ for $4 \mathrm{a}$ and $0.04 \mathrm{~cd}$ $\mathrm{A}^{-1}$ for $\mathbf{4 b}$ still remain low and can again be attributed to an unbalanced charge-carrier transport in the active materials. The EL-spectra in the inset of Fig. 8 show a broad and slightly structured EL emission peak for compound $4 \mathrm{a}$ in the range 410$570 \mathrm{~nm}$ with its maximum at $435 \mathrm{~nm}$ and a distinct shoulder 
ITO/PEDOT:PSS/4a,4b/TPBi/Ca/AI

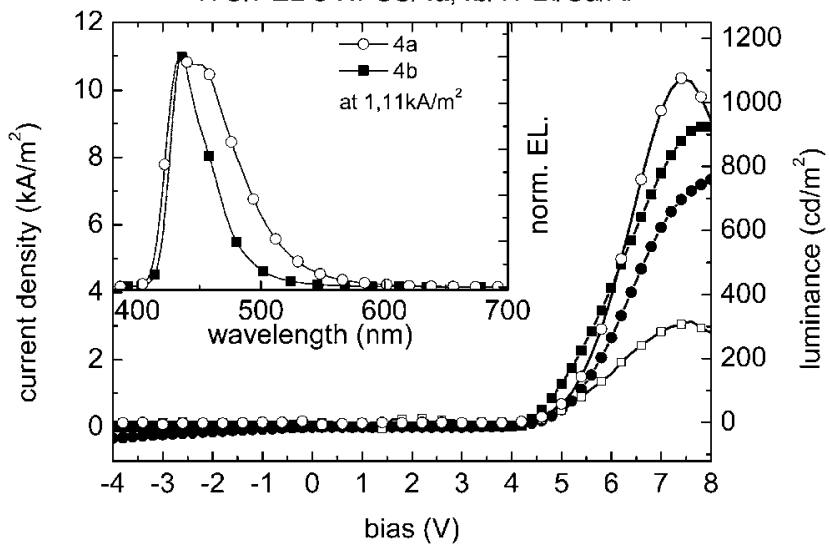

Fig. 8 Current density (4a: line with filled circles; $\mathbf{4 b}$ : line with filled squares)/ luminance (4a: line with open circles; $\mathbf{4 b}$ : line with open squares) as a function of the bias voltage of ITO/PEDOT:PSS/4a, $\mathbf{4 b} / \mathrm{TPBi} / \mathrm{Ca} / \mathrm{Al}$ devices. Inset: electroluminescence emission spectra at a current density of $1.11 \mathrm{kA} \mathrm{m}^{-2}$.

around $455 \mathrm{~nm}$. The spectrum corresponds to CIE1931 coordinates $x=0.151$ and $y=0.092$ (deep blue). For compound $4 \mathbf{b}$ a narrow and structureless molecular emission peak between $410 \mathrm{~nm}$ and $525 \mathrm{~nm}$, peaking at $435 \mathrm{~nm}$, can be observed, resulting in $x=0.156$ and $y=0.044$ (CIE1931), at the far blue end of the visible spectrum. None of the reported devices exhibited any sign of excimer emission.

The device work demonstrates that the tetrahydropyrene and pyrene-bridged compounds are in principle suitable emitting materials for deep-blue OLEDs. While the brightnesses and efficiencies are low compared to state-of-the-art multilayer electrophosphorescent devices employing iridium-based emitters, ${ }^{\mathbf{1 0 1 , 1 0 2}}$ some of present devices compare reasonably well to blue electrofluorescent devices with comparably simple device architectures, such as devices recently reported based on dendronized or polymerized pyrene derivatives; ${ }^{\mathbf{1 5 - 1 7}}$ for example a single-layer blue-turquoise device based on a polypyrene was reported to exhibit a peak luminance of $300 \mathrm{~cd} \mathrm{~m}^{-2}$ at $8 \mathrm{~V}$ and a maximum efficiency of $c a .0 .3 \mathrm{~cd} \mathrm{~A}^{-1}$. It is anticipated that more efficient OLEDs may be obtained by introduction of additional transport layers on the anode side to ensure a more balanced charge injection. ${ }^{103}$

\section{Conclusion}

Tetrahydropyrene derivatives $\mathbf{3 a} \mathbf{a}, \mathbf{b}$ show similar absorption and emission spectra to their biphenyl analogues, $\mathbf{2 a}$ and $\mathbf{2 b}$. The pyrene derivatives $\mathbf{4 a , b}$ show qualitatively different behavior: DFT calculations indicate significant differences in the key frontier orbitals and that the lowest-lying strong absorption is no longer $S_{0} \rightarrow S_{1}$, the emission is considerably red-shifted relative to that of the other compounds, and the fluorescence lifetimes are generally longer. All of the tert-butyl-substituted compounds studied have reversible electrochemistry, the first oxidation potential showing only minor variations with the bridging group. DFT calculations indicate significant variation in the reorganization energy for hole-transfer between biphenyl, tetrahydropyrene, and pyrene derivatives, with the smallest values being found for the pyrene materials. Both tetrahydropyrene and pyrene derivatives have been used as blue fluorescent emitters in simple OLED architectures; lower turn-on voltages for the pyrene materials may be related to more facile electron injection from the electron-transporting layer. These molecules may also have applications as hole-transporting materials and perhaps as hosts for green phosphors in OLEDs.

\section{Acknowledgements}

This work was supported by the Petroleum Research Foundation of the American Chemical Society (grant \#: 47343-B10), Solvay S.A., the Science and Technology Center Program of the National Science Foundation (DMR-0120967), and NSF PREM program (DMR-0934212). B. R. K. thanks AUB for faculty development funds.

\section{References}

1 C. W. Tang and S. A. VanSlyke, Appl. Phys. Lett., 1987, 51, 913-915.

2 K. Müllen and U. Scherf, Organic Light Emitting Devices. Synthesis, Properties and Applications, Wiley-VCH Verlag GmbH \& Co. KGaA, Weinheim, 2006.

3 L. Xiao, Z. Chen, B. Qu, J. Luo, S. Kong, Q. Gong and J. Kido, Adv. Mater., 2011, 23, 926-952.

4 Y.-H. Kim, S. J. Lee, S.-Y. Jung, K.-N. Byeon, J.-S. Kim, S. C. Shin and S.-K. Kwon, Bull. Korean Chem. Soc., 2007, 28, 443-446.

5 C. Tang, F. Liu, Y.-J. Xia, L.-H. Xie, A. Wei, S.-B. Li, Q.-L. Fan and W. Huang, J. Mater. Chem., 2006, 16, 4074-4080.

6 R. M. Adhikari, R. Mondal, B. K. Shah and D. C. Neckers, J. Org. Chem., 2007, 72, 4727-4732.

7 B. K. Shah, D. C. Neckers, J. Shi, E. W. Forsythe and D. Morton, J. Phys. Chem. A, 2005, 109, 7677-7681.

8 Y. Shirota and H. Kageyama, Chem. Rev., 2007, 107, 9531010.

9 M.-H. Ho, B. Balaganesan, T.-Y. Chu, T.-M. Chen and C. H. Chen, Thin Solid Films, 2008, 517, 943-947.

10 J. B. Birks, Photophysics of Aromatic Molecules, WileyInterscience, London, 1970.

11 T. Förster and K. Kasper, Z. Phys. Chem., 1954, 1, 275-277. 12 J. B. Birks, D. J. Dyson and I. H. Munro, Proc. R. Soc. London, Ser. A, 1963, 275, 575-588.

13 K. Kalyanasundaram and J. K. Thomas, J. Am. Chem. Soc., 1977, 99, 2039-2044.

14 C.-H. Yang, T.-F. Guo and I. W. Sun, J. Lumin., 2007, 124, 9398.

15 T. Qin, W. Wiedemair, S. Nau, R. Trattnig, S. Sax, S. Winkler, A. Vollmer, N. Koch, M. Baumgarten, E. J. W. List and K. Müllen, J. Am. Chem. Soc., 2011, 133, 1301-1303.

16 R. Trattnig, T. M. Figueira-Duarte, D. Lorbach, W. Wiedemair, S. Sax, S. Winkler, A. Vollmer, N. Koch, M. Manca, M. A. Loi, M. Baumgarten, E. J. W. List and K. Müllen, Opt. Express, 2011, 19, A1281-A1293. 
17 T. M. Figueira-Duarte, P. G. D. Rosso, R. Trattnig, S. Sax, E. J. W. List and K. Müllen, Adv. Mater., 2010, 22, 990-993.

18 Y. Tao, Q. Wang, L. Ao, C. Zhong, J. Qin, C. Yang and D. Ma, J. Mater. Chem., 2010, 20, 1759-1765.

19 L. Duan, J. Qiao, Y. Sun and Y. Qiu, Adv. Mater., 2011, 23, 1137-1144.

20 Y. Zhang, C. Zuniga, S.-J. Kim, D. Cai, S. Barlow, S. Salman, V. Coropceanu, J.-L. Brédas, B. Kippelen and S. R. Marder, Chem. Mater., 2011, 4002-4015.

21 N. Matsusue, Y. Suzuki and H. Naito,Jpn. J. Appl. Phys., Part 1, 2005, 44, 3691-3694.

22 J. Kido, K. Hongawa, K. Okuyama and K. Nagai, Appl. Phys. Lett., 1993, 63, 2627-2629.

23 Q. Zhang, Y. F. Hu, Y. X. Cheng, G. P. Su, D. G. Ma, L. X. Wang, X. B. Jing and F. S. Wang, Synth. Met., 2003, 137, 1111-1112.

24 S.-J. Kim, J. Leroy, C. Zuniga, Y. Zhang, L. Zhu, J. S. Sears, S. Barlow, J.-L. Brédas, S. R. Marder and B. Kippelen, Org. Electron., 2011, 12, 1314-1318.

25 G. Kremser, O. T. Hofmann, S. Sax, S. Kappaun, E. J. W. List, E. Zojer and C. Slugovc, Monatsh. Chem., 2008, 139, 223231.

26 Y. Wang, Y. Hua, X. Wu, L. Zhang, Q. Hou, F. Guan, N. Zhang, S. Yin and X. Cheng, Org. Electron., 2008, 9, 692-698.

27 Y. Tao, Q. Wang, C. Yang, Q. Wang, Z. Zhang, T. Zou, J. Qin and D. Ma, Angew. Chem., Int. Ed., 2008, 47, 8104-8107.

28 Z. Zhao, X. Xu, H. Wang, P. Lu, G. Yu and Y. Liu, J. Org. Chem., 2008, 73, 594-602.

29 C. Adachi, M. A. Baldo and S. R. Forrest, J. Appl. Phys., 2000, 87, 8049-8055.

30 J. F. Ambrose and R. F. Nelson, J. Electrochem. Soc., 1968, 115, 1159-1164.

31 J. F. Ambrose, L. L. Carpenter and R. F. Nelson, J. Electrochem. Soc., 1975, 122, 876-894.

32 G. Inzelt, J. Solid State Electrochem., 2003, 7, 503-510.

33 T. Yamada, F. Suzuki, A. Goto, T. Sato, K. Tanaka and H. Kaji, Org. Electron., 2011, 12, 169-178.

34 K. R. J. Thomas, J. T. Lin, Y.-T. Tao and C.-W. Ko, Adv. Mater., 2000, 12, 1949-1951.

35 Y. Xing, X. Xu, P. Zhang, W. Tian, G. Yu, P. Lu, Y. Liu and D. Zhu, Chem. Phys. Lett., 2005, 408, 169-173.

36 Z. Zhao, X. Xu, F. Wang, G. Yu, P. Lu, Y. Liu and D. Zhu, Synth. Met., 2006, 156, 209-214.

37 H.-C. Ting, Y.-M. Chen, H.-W. You, W.-Y. Hung, S.-H. Lin, A. Chaskar, S.-H. Chou, Y. Chi, R.-H. Liu and K.-T. Wong, J. Mater. Chem., 2012, 22, 8399-8407.

38 D. M. Connor, S. D. Allen, D. M. Collard, C. L. Liotta and D. A. Schiraldi, J. Org. Chem., 1999, 64, 6888-6890.

39 D. Rausch and C. Lambert, Org. Lett., 2006, 8, 5037-5040.

40 H. Lee and R. G. Harvey, J. Org. Chem., 1986, 51, 2847-2848.

41 Y. Liu, M. Nishiura, Y. Wang and Z. Hou, J. Am. Chem. Soc., 2006, 128, 5592-5593.

42 B. E. Koene, D. E. Loy and M. E. Thompson, Chem. Mater., 1998, 10, 2235-2250.

43 Q. Zhang, J. Chen, Y. Cheng, L. Wang, D. Ma, X. Jing and F. Wang, J. Mater. Chem., 2004, 14, 895-900.
44 R. Anemian, Y. Morel, P. L. Baldeck, B. Paci, K. Kretsch, J.-M. Nunzi and C. Andraud, J. Mater. Chem., 2003, 13, 2157-2163.

45 SAINT+; 6.2a, Bruker Analytical X-ray System, Inc., Madison, WI, 2001.

$46 S A D A B S$, Bruker Analytical X-ray System, Inc., Madison, WI, 1999.

47 SHELXTL; 6.10, Bruker Analytical X-ray System, Inc., Madison, WI, 1997.

48 A. D. Becke, J. Chem. Phys., 1993, 98, 5648-5652.

49 C. Lee, W. Yang and R. G. Parr, Phys. Rev. B: Condens. Matter Mater. Phys., 1988, 37, 785-789.

50 S. H. Vosko, L. Wilk and M. Nusair, Can. J. Phys., 1980, 58, 1200-1211.

51 P. J. Stephens, F. J. Devlin, C. F. Chabalowski and M. J. Frisch, J. Phys. Chem., 1994, 98, 11623-11627.

52 P. C. Hariharan and J. A. Pople, Theor. Chim. Acta, 1973, 28, 213-222.

53 M. M. Francl, W. J. Pietro, W. J. Hehre, J. S. Binkley, M. S. Gordon, D. J. Defrees and J. A. Pople, J. Chem. Phys., 1982, 77, 3654-3665.

54 M. J. Frisch, G. W. Trucks, H. B. Schlegel, G. E. Scuseria, M. A. Robb, J. R. Cheeseman, G. Scalmani, V. Barone, B. Mennucci, G. A. Petersson, H. Nakatsuji, M. Caricato, X. Li, H. P. Hratchian, A. F. Izmaylov, J. Bloino, G. Zheng, J. L. Sonnenberg, M. Hada, M. Ehara, K. Toyota, R. Fukuda, J. Hasegawa, M. Ishida, T. Nakajima, Y. Honda, O. Kitao, H. Nakai, T. Vreven, J. A. Montgomery, Jr, J. E. Peralta, F. Ogliaro, M. Bearpark, J. J. Heyd, E. Brothers, K. N. Kudin, V. N. Staroverov, R. Kobayashi, J. Normand, K. Raghavachari, A. Rendell, J. C. Burant, S. S. Iyengar, J. Tomasi, M. Cossi, N. Rega, J. M. Millam, M. Klene, J. E. Knox, J. B. Cross, V. Bakken, C. Adamo, J. Jaramillo, R. Gomperts, R. E. Stratmann, O. Yazyev, A. J. Austin, R. Cammi, C. Pomelli, J. W. Ochterski, R. L. Martin, K. Morokuma, V. G. Zakrzewski, G. A. Voth, P. Salvador, J. J. Dannenberg, S. Dapprich, A. D. Daniels, O. Farkas, J. B. Foresman, J. V. Ortiz, J. Cioslowski and D. J. Fox, Gaussian 09, Revision A.02, Gaussian, Inc., Wallingford CT, 2009.

55 H. Volmmann, H. Becher, M. Corell and H. Streeck, Justus Liebigs Ann. Chem., 1937, 531, 1-159.

56 A. G. Crawford, A. D. Dwyer, Z. Liu, A. Steffen, A. Beeby, L.-O. Palsson, D. J. Tozer and T. B. Marder, J. Am. Chem. Soc., 2011, 133, 13349-13362.

57 A. Hameurlaine and W. Dehaen, Tetrahedron Lett., 2003, 44, 957-959.

58 M. S. Driver and J. F. Hartwig, J. Am. Chem. Soc., 1996, 118, 7217-7218.

59 J. P. Wolfe, S. Wagaw and S. L. Buchwald, J. Am. Chem. Soc., 1996, 118, 7215-7216.

60 H. Nakashima, S. Kawakami, S. Shitagaki and S. Seo, US Pat. 2007/0096639, 2007.

61 P. J. Low, M. A. J. Paterson, D. S. Yufit, J. A. K. Howard, J. C. Cherryman, D. R. Tackley, R. Brook and B. Brown, J. Mater. Chem., 2005, 15, 2304-2315. 
62 Although biphenyl was formerly considered as adopting a planar conformation in the crystal (J. Trotter, Acta Crystallogr., 1961, 14, 1135; A. Hargreaves and A. H. Rizvi, Acta Crystallogr., 1962, 15, 365), this was subsequently found to be an artefact of disorder, with a phase transition being observed to give an ordered phase below $40 \mathrm{~K}$ with the twist angle of $c a .10^{\circ}$ in that phase (H. Cailleau, J. L. Baudour and C. M. E. Zeyen, Acta Crystallogr., Sect. B: Struct. Crystallogr. Cryst. Chem., 1979, 35, 426); moreover, when found in general positions within other structures, biphenyl molecules are also found to be twisted (e.g., D. Naae, Acta Crystallogr., Sect. B: Struct. Crystallogr. Cryst. Chem., 1979, 35, 2765; A. Pénicaud, O. Y. Carréon, A. Perrier, D. J. Watkin and C. Coulon, J. Mater. Chem. 2002, 12, 913; R. E. Douthwaite, A. Taylor and A. C. Whitwood, Acta Crystallogr., Sect. C: Cryst. Struct. Commun., 2005, 61, o328).

63 W. Li, J. Qiao, L. Duan, L. Wang and Y. Qiu, Tetrahedron, 2007, 63, 10161-10168.

64 M. A. Reddy, A. Thomas, B. Sridha, V. J. Rao and K. Bhanuprakash, Tetrahedron Lett., 2011, 52, 6942-6947.

65 W. Wu and J. Tong, Acta Crystallogr., Sect. E: Struct. Rep. Online, 2011, 67, 01919.

66 S. Saha and S. Samanta, Acta Crystallogr., Sect. C: Cryst. Struct. Commun., 1999, 55, 1299-1300.

67 F. H. Allen, O. Kennard, D. G. Watson, L. Brammer, A. G. Orpen and R. Taylor, J. Chem. Soc., Perkin Trans. 2, 1987, S1-S19.

68 V. Jankus, C. Winscom and A. P. Monkman, J. Chem. Phys., 2009, 130, 074501.

69 I. B. Berlman, Handbook of Fluorescence Spectra of Aromatic Molecules, Academic Press, New York, 2nd edn, 1971.

70 The effects of electron self-interaction errors in the general DFT formalism can often lead to red-shifted absorption spectra for conjugated systems.

71 J. V. Goodpaster, J. F. Harrison and V. L. McGuffin, J. Phys. Chem. A, 1998, 102, 3372-3381.

72 Y. Bito, N. Shida and T. Toru, Chem. Phys. Lett., 2000, 328, 310-315.

73 M. Parac and S. Grimme, Chem. Phys., 2003, 292, 11-21.

74 S. Grimme and M. Parac, ChemPhysChem, 2003, 4, 292-295.

75 B.-C. Wang, J.-C. Chang, H.-C. Tso, H.-F. Hsu and C.-Y. Cheng, J. Mol. Struct.: THEOCHEM, 2003, 629, 11-20.

76 M. Dierksen and S. Grimme, J. Chem. Phys., 2004, 120, 3544-3554.

77 Y. H. Park and B.-S. Cheong, Curr. Appl. Phys., 2006, 6, 700-705.

78 I. S. K. Kerkines, I. D. Petsalakis, G. Theodorakopoulos and W. Klopper, J. Chem. Phys., 2009, 131, 224315.

79 O. K. Bazyl, G. V. Maier, T. N. Kopylova and V. I. Danilova, Zh. Prikl. Spektrosk., 1982, 37, 80-86.

80 S. Grimme and F. Neese, J. Chem. Phys., 2007, 127, 154116.

81 A. Sharma and S. Schulman, Introduction to Fluorescence Spectroscopy, Wiley-Interscience, USA, 1999.
82 J. L. Kropp, W. R. Dawson and M. W. Windsor, J. Phys. Chem., 1969, 73, 1747-1752.

83 S. Krotkus, K. Kazlauskas, A. Miasojedovas, A. Gruodis, A. Tomkeviciene, J. V. Grazulevicius and S. Jursenas, J. Phys. Chem. C, 2012, 116, 7561-7572.

84 J. D. Anderson, E. M. McDonald, P. A. Lee, M. L. Anderson, E. L. Ritchie, H. K. Hall, T. Hopkins, E. A. Nash, J. Wang, A. Padias, S. Thayumanavan, S. Barlow, S. R. Marder, G. Jabbour, S. Shaheen, B. Kippelen, N. Peyghambarian, R. M. Wightman and N. R. Armstrong, J. Am. Chem. Soc., 1998, 120, 9646-9655.

85 C. Risko, V. Coropceanu, S. Barlow, V. Geskin, K. Schmidt, N. E. Gruhn, S. R. Marder and J.-L. Brédas, J. Phys. Chem. C, 2008, 112, 7959-7967.

86 F. Scholz, Electroanalytical Methods: Guide to Experiments and Applications, Springer, New York, 2002.

87 C. Lambert and G. J. Nöll, J. Am. Chem. Soc., 1999, 121, 8434-8442.

88 J. E. Sutton and H. Taube, Inorg. Chem., 1981, 20, 31253134.

89 However, a rather different UV-PES value of $6.25 \mathrm{eV}$ has also been reported for 2 a (A. Kahn, N. Koch and W. Gao, J. Polym. Sci., Part B: Polym. Phys., 2003, 41, 2529).

90 J. Hankache and O. S. Wenger, Chem. Rev., 2011, 111, 51385178.

91 T. Bally and W. T. Borden, Reviews in Computational Chemistry, Wiley-VCH, New York, 1999.

92 P. J. Low, M. A. J. Paterson, H. Puschmann, A. E. Goeta, J. A. K. Howard, C. Lambert, J. C. Cherryman, D. R. Tackley, S. Leeming and B. Brown, Chem.-Eur. J., 2004, 10, 83-91.

93 V. Coropceanu, M. Malagoli, J. M. André and J.-L. Brédas, J. Am. Chem. Soc., 2002, 124, 10519-10530.

94 R. A. Marcus, Rev. Mod. Phys., 1993, 65, 599-610.

95 M. Malagoli and J.-L. Brédas, Chem. Phys. Lett., 2000, 327, 13-17.

96 R. D. Hreha, C. P. George, A. Haldi, B. Domercq, M. Malagoli, S. Barlow, J.-L. Brédas, B. Kippelen and S. R. Marder, Adv. Funct. Mater., 2003, 13, 967-973.

97 V. Coropceanu, M. Malagoli, D. A. da Silva Filho, N. E. Gruhn, T. G. Bill and J.-L. Brédas, Phys. Rev. Lett., 2002, 89, 275503.

98 D. A. da Silva Filho, V. Coropceanu, D. Fichou, N. E. Gruhn, T. G. Bill, J. Gierschner, J. Cornil and J.-L. Brédas, Philos. Trans. R. Soc., A, 2007, 365, 1435-1452.

99 Z. Wang, P. Lu, S. Chen, Z. Gao, F. Shen, W. Zhang, Y. Xu, H. S. Kwok and Y. Ma, J. Mater. Chem., 2011, 21, 5451-5456.

100 L. Qian, D. Bera and P. H. Holloway, Appl. Phys. Lett., 2007, 90, 103511.

101 Y.-C. Zhu, L. Zhou, H.-Y. Li, Q.-L. Xu, M.-Y. Teng, Y.-X. Zheng, J.-L. Zuo, H.-J. Zhang and X.-Z. You, Adv. Mater., 2011, 23, 4041-4046.

102 C. Ulbricht, B. Beyer, C. Friebe, A. Winter and U. S. Schubert, Adv. Mater., 2009, 21, 4418-4441.

103 Y. Shen, A. R. Hosseini, M. H. Wong and G. G. Malliaras, ChemPhysChem, 2004, 5, 16-25. 